\title{
High-Resolution Seismic Characterization of the Gas and Gas Hydrate System at Green Canyon 955, Gulf of Mexico, USA
}

Seth S. Haines ${ }^{a}$, Patrick E. Hart ${ }^{b}$, Timothy S. Colletta, William Sheddc, Matthew Fryed, Paul Weimere, Ray Boswell ${ }^{\mathrm{f}}$

a USGS Central Energy Resources Science Center, Box 25046 MS 939, Denver Federal Center, Denver, CO 80225, USA.

b USGS Pacific Coastal and Marine Science Center, 2885 Mission Street 999 Santa Cruz CA 95060 USA.

c Bureau of Ocean Energy Management, 1201 Elmwood Park Blvd, New Orleans LA 70123, USA

d Bureau of Ocean Energy Management, 45600 Woodland Road Sterling VA 20166, USA

e University of Colorado at Boulder Department of Geological Sciences, Boulder, CO, UCB 399, Boulder, CO 80309-0399, USA.

f Department of Energy, National Energy Technology Laboratory, Morgantown, WV, USA.

Corresponding author: Seth S. Haines, shaines@usgs.gov, (303) 236-5709. 


\section{Abstract}

The Pliocene and Pleistocene sediments at lease block Green Canyon 955 (GC955) in the Gulf of Mexico include sand-rich strata with high saturations of gas hydrate; these gas hydrate accumulations and the associated geology have been characterized over the past decade using conventional industry 3-dimensional (3D) seismic data and dedicated logging-while-drilling (LWD) borehole data. To improve structural and stratigraphic characterization and to address questions of gas flow and reservoir properties, in 2013 the U.S. Geological Survey acquired highresolution two-dimensional (2D) seismic data at GC955. Combined analysis of all available data improves our understanding of the geological evolution of the study area, which includes basin-scale migration of the Mississippi River sediment influx as well as local-scale shifting of sedimentary channels at GC955 in response to saltdriven uplift, structural deformation associated with the salt uplift, and upward gas migration from deeper sediments that charges the main gas hydrate reservoir and shallower strata. The 2D data confirm that the sand-rich reservoir is composed principally of sediments deposited in a proximal levee setting and that episodes of channel scour, interspersed with levee deposition, have resulted in an assemblage of many individual proximal levee deposit "pods" each with horizontal extent up to several hundred meters. Joint analysis of the 2D and 3D data reveals new detail of a complex fault network that controls the fluid flow system; large east-west trending normal faults allow fluid flow through the reservoir-sealing fine-grained unit, and smaller north-south oriented faults provide focused fluid-flow pathways (chimneys) through the shallower sediments. This system has enabled the flow of gas from the 
main reservoir to the seafloor throughout the recent history at GC955, and its intricacies help explain the distributed occurrences of gas hydrate in the intervening strata.

Keywords: gas hydrate, seismic reflection, Gulf of Mexico, gas chimney, focused fluid flow.

\section{Introduction}

Naturally occurring gas hydrate accumulations have been identified in numerous marine and permafrost areas around the world (Kvenvolden, 1993; Collett et al., 2009). These deposits have been characterized through extensive geophysical, coring, and borehole-logging studies that have revealed complex systems consisting of gas accumulations, gas hydrate deposits, and fluid-flow pathways. Deposits of gas hydrate can be in one or more of several forms, with the most common including gas hydrate within the pore space of sandy or other coarse-grained strata, and as gas hydrate within fractures or dispersed in fine-grained sediments (Collett et al., 2009). Fluid-flow pathways include bedding planes and faults, as well as chimneys and related features that act as conduits for gas and other fluids (e.g., Bünz et al., 2003; Judd and Hovland, 2007; Løseth et al., 2009; Crutchley et al., 2010; Ryu et al., 2013; Plaza-Faverola et al., 2015). Sand-hosted gas hydrate accumulations are of particular interest from an energy resource standpoint, because globally they represent a considerable quantity of natural gas (Boswell and Collett, 2011), and 
because recent studies indicate that the gas can be produced using existing technologies (Boswell et al., 2014).

The Gulf of Mexico contains a well-developed petroleum system with a long history of oil and gas production. Gas hydrate accumulations have been identified and studied by a number of groups, including the Gulf of Mexico Gas Hydrate Joint Industry Project (JIP), which existed from 2005 to 2012 (http://www.netl.doe.gov/research/oil-and-gas/methane-hydrates/2009-gom-jip; Ruppel et al., 2008; Boswell et al., 2012a). Extensive geophysical studies indicate gas hydrate accumulations at several sites, and borehole studies conducted in 2005 - acquiring logging-while-drilling (LWD), wireline, and core data - confirmed gas hydrate at lease blocks Atwater Valley 13 and 14 and Keathley Canyon 151 (Ruppel et al., 2008). Acquisition of LWD data at three additional sites in 2009 confirmed the presence of significant sand-hosted gas hydrate deposits at lease blocks Green Canyon 955 (GC955) and Walker Ridge 313 and found indications of possible gas hydrate in shallow sand layers at Alaminos Canyon 21 (Boswell et al., 2012a). The GC955 site (Figure 1) has emerged as an area of particular interest due to the presence of high saturations of gas hydrate (approximately 80\%) in sand-rich units as thick as approximately $30 \mathrm{~m}$ (Boswell et al., 2012b, Lee and Collett, 2012; Cook et al., 2012).

The primary stratigraphic interval of interest at GC955 is composed of Pleistocene channel/levee deposits at a depth of approximately $500 \mathrm{~m}$ below seafloor. 
Underlying salt bodies have caused uplift and faulting of a portion of the main reservoir body, resulting in a four-way closure structure (dome) that shows relatively high amplitudes in seismic reflection data (McConnell et al., 2010). The JIP drilled, and acquired LWD data in, three boreholes at GC955, with wells GC955-H and GC955-Q in the structurally highest area and well GC955-I just off the edge of the main structure and proximal to a seismically identified channel feature.

Together the LWD data indicate a heterogeneous distribution of pore-filling materials at GC955 (Figure 2), with a stack of thin gas-hydrate-saturated sand layers overlying water-saturated layers in the main reservoir interval at well GC955- $\mathrm{H}$ and gas hydrate overlying inferred free gas in the same strata just one kilometer away at well GC955-Q (Boswell et al., 2012a). Furthermore, in the shallower section (250 to $350 \mathrm{~m}$ below the seafloor) well GC955-H encountered fracture-filling gas hydrate in a fine-grained interval that showed no gas hydrate at well GC955-Q (Lee and Collett, 2012; Cook et al., 2012). Well GC955-I confirmed the presence of sand containing modest amounts of gas hydrate.

Due to the lower frequency sound source, the 3D data provide only a low-resolution image of the gas hydrate reservoirs, thus leaving many questions pertaining to development and evolution of the gas hydrate system and to characteristics of the reservoir strata. In addition, available data indicate significant heterogeneity in the pore-filling materials through the area, but provide an incomplete understanding of the controls on this observed heterogeneity. To address these persistent questions and others, in 2013 the U.S. Geological Survey acquired high-resolution seismic data 
at GC955 (Figure 1), as described by Haines et al. (2014a, 2014b). These data provide many valuable insights regarding the geologic setting and gas and gas hydrate system at GC955, allowing refinement of models for sedimentary deposition and structural deformation, as well as for fluid flow.

In this contribution, we outline the geologic setting and previous gas hydrate studies at GC955, and then we present a suite of refinements to this geologic model based on the 2013 high-resolution seismic data. Next, we describe the major fluid-flow paths in the gas and gas hydrate system, providing an explanation for the distributions of these materials observed in the JIP boreholes. Finally, we estimate the possible volume of total gas resource present as gas hydrate in the main sandrich reservoir at GC955 and discuss the likely reservoir characteristics based on the interpreted depositional setting.

\section{Background}

\section{$\underline{2.1 \text { Geologic Setting }}$}

Lying $330 \mathrm{~km}$ south of New Orleans and just basinward of the Sigsbee Escarpment, GC955 includes water depths ranging from 1975 to $2250 \mathrm{~m}$. Since the late Miocene, the area has been subject to intervals of channel depositional processes associated with the Mississippi fan (Weimer, 1989). Periods of channel erosion and deposition have been interspersed with periods of fine-grained sediment deposition as the position of the main channel migrated across the continental shelf. Weimer (1989) interprets two distinct episodes when channels of the Mississippi fan system were 
present in the area of GC955, referring to these channels as \#1 and \#12. The second of these features (channel 12) was formed approximately 500 ka (Weimer and Dixon, 1994), and resulted in a package of channel/levee deposits that are evident within the upper 600 meters at GC955. The lowest part of this sedimentary sequence is a sand-rich accumulation body that is up to approximately 250 meters thick at GC955; this is the primary target horizon for gas hydrate studies (McConnell et al., 2010; Boswell et al., 2012a).

The fundamental geologic features of the GC955 area may be seen in Figure 2a, which displays a profile from petroleum-industry-acquired 3D seismic data along an east-west transect that intersects wells GC955-Q and GC955-H (Figure 1). The main reservoir body lies at a two-way travel time (twtt) of approximately $3.2 \mathrm{~s}$, and it shows significant structural complexity and relatively high reflection amplitudes. Farther to the east, this unit is at greater depth but it shows a somewhat similar appearance and relatively lower-amplitude seismic reflectivity (McConnell et al., 2000). Above the main reservoir interval lie approximately $500 \mathrm{~m}$ of more recent deposits, which to the east includes a number of individually identifiable channel features. These shallow deposits show generally lower amplitudes and greater lateral homogeneity than the deeper reservoir body (Figure 2).

The area of GC955 has been impacted by considerable structural deformation, largely related to salt movement. The site is located a few kilometers basinward of the Sigsbee Escarpment (generally considered to represent the outboard edge of salt 
tectonics in the Gulf of Mexico), but several salt features exist in the area. A salt diapir crops out at the nearby Green Knoll (Figure 1), and a second salt feature is located directly beneath the study site (Figures 1 and 2). The underlying salt feature is oblong in map view, extending roughly north-south, and it is responsible for uplift and associated faulting of the overlying strata, including the main reservoir body. This deformation has resulted in a domed character, and thus a four-way dipping structural closure at the main reservoir level (McConnell et al., 2010).

\subsection{Previous gas hydrate studies}

The Pleistocene channel/levee deposits at GC955 were identified as a potential reservoir of sand-hosted gas hydrate deposits by Jones et al. (2008) and Hutchinson et al. (2009), based on well logs from a nearby industry well (Figure 1) and on industry 3D seismic data. Gamma logs from the industry well indicated the potential for sand in the main reservoir at GC955 (Jones et al., 2008) and the combination of resistivity logs and broader inferences of a shallow gas system suggested that these sands contain gas hydrate. The seismic data suggest that the sand units exist in the area where wells GC955-H and GC955-Q were ultimately drilled, and that the four-way closure structure may have trapped gas migrating upward from deeper strata. The presence of migrating gas in the GC955 area is indicated by seismic analysis (Heggland, 2004), although the exact location for this study is not specified in that publication. Potential drilling locations were identified based on observations of strong positive-polarity seismic arrivals interpreted to indicate sand intervals with high gas-hydrate saturations (Hutchinson et al., 2009), 
based on interval amplitude (McConnell et al., 2010; Boswell et al 2012a), and based on gas hydrate saturation estimates drawn from seismic impedance inversion (Shelander et al., 2010; 2012).

Logging-while-drilling data acquired in 2009 show the gas hydrate distribution at GC955 to be approximately as predicted by pre-drill studies. Where well GC955-H penetrates the main reservoir body (Figures 1 and 2), LWD data indicate approximately $30 \mathrm{~m}$ of sand-rich strata, with gas hydrate saturations of approximately $80 \%$ in the sand layers, underlain by water-bearing sand layers (Boswell et al., 2012b; Lee and Collett, 2012). One kilometer away at the location of well GC955-Q (Figures 1 and 2), LWD data indicate hydrate-bearing sand, inferred to be underlain by free gas (Zhang et al., 2012; McConnell et al., 2012). LWD data show that shallower fine-grained sediments, between 250 and $350 \mathrm{~m}$ depth below seafloor, contain fracture-filling gas hydrate at GC955-H and only pore water at well GC955-Q (Lee and Collett, 2012; Cook et al., 2012). Farther north, and at the edge of the four-way closure structure, well GC955-I (Figure 1) found only very minimal gas hydrate within the main reservoir, but did confirm the presence of sand in that layer (Boswell et al., 2012b).

The 2009 LWD data provide a wealth of information regarding the geologic setting and gas and gas hydrate system at GC955, and in combination with industry 3D seismic data enable a broad suite of interpretations at the site, as summarized by Boswell et al. (2012a). These data also highlight a number of questions regarding 
key details of the geologic history, the formation and evolution of the gas and gas hydrate system, and the controls on reservoir compartmentalization and heterogeneous fluid saturation at GC955. Specifically, controls on the contrasting gas and gas hydrate distribution observed in wells GC955-H and GC955-Q, less than a kilometer apart, were not clearly established. Log and seismic data indicate that the main reservoir is a package of sand and shale layers, such as might be anticipated (e.g., Clemenceau et al., 2000; Bramlett and Craig, 2002) to have greater connectivity than what is indicated by the LWD-data-inferred isolated reservoir zones. Similar questions are raised by the hydrate distribution in the shallower gas hydrate bearing strata.

\section{High-resolution data}

In order to address the outstanding questions at GC955, the USGS acquired highresolution multichannel 2D seismic data at the site in 2013 (Haines et al., 2014a). Data acquisition at GC955 included approximately $400 \mathrm{~km}$ of 2D seismic transects in a rough grid with line spacing as close as $50 \mathrm{~m}$ near the wells (Figure 1), and also a set of longer lines (up to approximately $20 \mathrm{~km}$ ) at various azimuths. The data were recorded with a 500-m, 72-channel digital hydrophone streamer. Seismic energy was provided by a pair of 105/105 in ${ }^{3}$ generator-injector airguns that provide energy to approximately $250 \mathrm{~Hz}$, with a center frequency between 100 and $125 \mathrm{~Hz}$ resulting in a wavelength of approximately $15 \mathrm{~m}$ (for the non-hydrate-saturated sediments). 
Miller et al. (2016) describe the data processing that was applied to the 2013 seismic data. Several forms of strong coherent noise necessitated development and application of non-standard noise removal approaches. The data were migrated with a post-stack Stolt FK time migration algorithm, using smoothed interval velocities estimated from the moveout velocities. In this contribution, we focus on the results from the "true-relative-amplitude" processing flow detailed by Miller et al. (2016). This processing flow made use of a specialized waveform deconvolution approach aimed at providing correct relative amplitudes within each seismic line (but not necessarily true relative amplitudes between the various seismic lines). Because these are 2D data acquired in areas of complex 3D geology, energy from out of the plane of the seismic transect is expected and it cannot be migrated properly.

Unlike previously available seismic datasets, the 2013 seismic data were acquired specifically for imaging shallow targets, and thus are well suited to our gas hydrate studies. The 2013 seismic data provide at least three times finer vertical resolution than the previously available 3D seismic data (Figure 2; Haines et al., 2014b) and similarly improved lateral resolution, due to the smaller Fresnel zone. The 3D data were acquired with inline and cross-line spacings of 12.5 and $20 \mathrm{~m}$, respectively, and a sound source with a center frequency of approximately $35 \mathrm{~Hz}$ (wavelength approximately $50 \mathrm{~m}$ ). As shown in Figure 2, and as discussed and illustrated in greater detail by Haines et al. (2014b), we can see more individual reflections and improved resolution of structural complexity and reservoir heterogeneity in the 2D data as compared with the available 3D data. For all figures in this paper, both the 
3D and the high-resolution 2D data are displayed in time, rather than depth, because robust depth conversion or depth migration has not been performed. A reasonable approximation for areas within $400 \mathrm{~m}$ of the seafloor is that $0.1 \mathrm{~s}$ of two-way travel time is equivalent to approximately $80 \mathrm{~m}$ of sedimentary thickness.

\section{Geologic and fluid-related observations}

\subsection{High resolution imaging of the geologic setting}

Visual inspection of the high-resolution 2D data reveals considerable fine-scale detail within the main reservoir (Figure 2), including numerous high-amplitude stacked reflections within the areas penetrated by wells GC955-Q and GC955-H. We see considerably greater detail in the adjacent and overlying strata, including a north-south oriented fault system with generally small fault offsets, and a local unconformity that provides a useful marker for later discussions (Figures 2 and 3). East of the primary study area, individual channels features are evident (Figure 2), and the generally planar reflections within the channel fill indicate depositional processes distinct from those occurring during deposition of the stratigraphically deeper sediments in the main GC955 reservoir (Figure 2). To the west of the main study area we observe accumulated debris flow deposits (indicated in Figures 2 and 4), likely due to mass transport from up-slope (likely out of the plane of the data). These deposits show a mostly chaotic seismic character, with a few distinct coherent blocks as marked on Figure 4. 
The high-resolution 2D data, together with the lower-resolution 3D data, provide a more detailed understanding of the fault systems in the area than was previously possible (Boswell et al., 2012b). Marked in pink on the upper plot in Figure 2 is a horizon that we picked throughout the available 3D data volume. Two oblique views of this surface are shown in Figure 5, illustrating that a fault structure exists within the uplifted dome, resulting in an east-west oriented crestal graben. As is evident from the 3D surface and 2D images shown in Figure 5, the nature of the large east-west striking normal faults varies along the graben. In the east, motion is accommodated by multiple normal faults on each side of the graben. In the west, the graben is narrower and motion on each side of the graben is largely accommodated by a single normal fault with greater throw than the faults on the eastern end of the graben. The graben faults appear to extend from deep in the section, through the reservoir, up to the depth of the unconformity (Figure 6 parts $b$ and c). Due to the fault geometry and the distribution of the reservoir sediments, the shallowest area of the main reservoir body (located where wells GC955-H and GC955-Q penetrate it) does not directly overlie the shallowest part of the surface plotted in Figure 5.

In addition to the large graben faults, a second set of faults strike in an approximately north-south direction (Figures 3 and 6a). The north-south striking faults generally show less throw than the graben faults and may therefore be shorter-lived. Like the graben faults, the north-south striking faults show normal offset, possibly due to extensional forces associated with dome uplift or subsidence 
in response to stratigraphic compaction or structural deformation of underlying sediments, or perhaps a combination of the two. The interplay between the two fault systems at GC955 has important ramifications that are described in the next section.

\subsection{Fluid flow, gas, and gas hydrate}

In the area of GC955, thermogenic gas is assumed to originate at depth and to migrate upward into the GHSZ along fractures associated with the underlying salt feature (e.g., Heggland 2004). The gas may have experienced local microbial "recycling" that could lead to it having a microbial chemical signature, however (e.g., Paull et al., 1994). High seismic reflection amplitudes observed in the 3D data beneath the main reservoir (Figure 6) suggest that free gas is present within some strata in some of the fault blocks, in particular within the structurally high areas where gas would be expected to accumulate. Overall, the main reservoir body shows high seismic reflection amplitudes, and it acoustically masks the deeper strata. This observation is consistent with the presence of gas and gas hydrate throughout the main reservoir but it does not indicate degree of saturation. In this section we describe details of the evolution and dynamics of the gas and gas hydrate system at GC955 provided by the 2013 high-resolution seismic data, building from what was discussed by Haines et al. (2014b) and previously identified at a broad scale by Heggland (2004) and Boswell et al. (2012b). 
We interpret that the sedimentary unit immediately overlying the reservoir acts broadly as a seal suppressing escape of gas from the reservoir, based on its generally transparent and laterally uniform appearance in seismic data (Figures 2 and 6), and based on gamma log data indicating uniformly clay-rich sediments (Collett et al., 2012). In the area of well GC955-H (Figures 5b and 6c), the main reservoir seal appears to be breached, based on observations of gas and gas hydrate above the reservoir and a vent at the seafloor. We note that in the area of GC955-H multiple faults accommodate motion on the south side of the graben (Figures $5 b$ and 6c); these faults penetrate the main reservoir at its thickest and shallowest point along this north-south transect. We suggest that the graben faults provide conduits for gas flow through the low-permeability unit, as shown in Figure 6c, allowing gas to migrate from the reservoir to the overlying strata. From the top of the lowpermeability unit, upward gas migration continues via the focused flow pathways that are visible in Figure 6a.

In contrast to what we see near well GC955-H, in the area of well GC955-Q (Figures $5 a$ and $6 \mathrm{~b}$ ), a single normal fault accommodates motion on the south side of the graben; this fault penetrates the reservoir in a thin and low-standing area. As with its eastern counterparts, this fault provides a potential conduit for gas through the low-permeability unit, but we interpret that less gas is available due to the fault intersecting the reservoir south of the thickest and shallowest area (which is at the location of well GC955-Q). LWD data indicate that gas may have accumulated in the thick, high-standing, part of the main reservoir at well GC955-Q, unlike at well 
GC955-H where no free gas is inferred to exist (Figure 2; Boswell et al., 2012b; Collett et al., 2012). This gas accumulation exists in an area where the lowpermeability unit is not intersected by large-scale graben faults and thus the gas is trapped in the main reservoir. Small-throw north-south striking normal faults exist around well GC955-Q (Figures 3 and 6a), representing potential fluid-flow pathways above the low-permeability unit, but the gas in the main reservoir cannot reach these faults due to the absence of large graben faults to breach the low-permeability unit (Figures 5 and 6b).

Figure 7 shows detail of the focused fluid flow features in two orientations; for simplicity we refer to these features as "chimneys". Seismic transect 221 (Figure 7b) is parallel to, and $100 \mathrm{~m}$ south of, line 225a (Figure 6a); these two lines provide complementary east-west cross-sectional views of three chimney features. In these east-west views, the chimneys are apparent as narrow subvertical zones with minimal coherent seismic reflectivity and upwarped seismic reflections at their flanks. Based on the orientation of the chimneys and on the presence of many smallthrow north-south striking faults in the sediments above the low-permeability unit, we interpret that the chimneys represent focused gas flow along pre-existing faults. The focused flow pathways (chimneys) are essentially planar, in contrast to columnar features identified in other areas (e.g., Ryu et al., 2013; Plaza-Faverola et al., 2015). Each chimney at GC955 shows a north-south extent of approximately 600 $m$ and an east-west extent of just a few tens of meters. They are spaced at intervals of approximately $100 \mathrm{~m}$. The westernmost chimney extends to a seafloor feature 
visible in the bathymetry shown in Figure 7a, identified by Heggland (2004) as a mud volcano or seafloor vent; the feature is a few tens of meters in diameter and just a few meters in height; its presence indicates that seafloor venting is occurring, or has occurred within recent geologic time, in only one location and thus that fluid flow is not presently occurring along the full extent of the planar fluid flow pathways. At the top of the easternmost chimney, an anomalously bright, downward-concave, seismic reflection at the depth of the unconformity indicates a possible relict seafloor seep feature. The amplitude and positive polarity indicate a strong positive impedance contrast, likely due to accumulated gas hydrate or authigenic carbonate precipitation.

North-south oriented seismic lines 145 and 153a (Figure 7c and d) provide parallel views through a chimney (line 145) and through the adjacent strata approximately $250 \mathrm{~m}$ to the east (line 153a). In the area of the chimney (line 145, Figure 7c) we see that seismic reflectivity is generally incoherent, whereas in the area adjacent to but outside of the chimney (line 153a, Figure 7d) we observe that seismic reflectivity is generally coherent throughout the section between the lowpermeability unit and the seafloor. A small zone of limited reflectivity is marked on line 153a in Figure 7d; its origin is uncertain and it may be due to disturbed strata due to small-scale gas flow, or to seismic imaging complexities. In the area of the chimney, and evident along its north-south extent, a patch of high-reflectionamplitude material exists at the seafloor (line 145, in Figure 7c); we interpret this material as deposits associated with long-term seepage and north-south migration 
of the seafloor seepage feature over time, or possibly the presence of a linear seafloor vent at some point in the past.

The up-warped character of the reflections at the chimney flanks (evident in the east-west seismic lines in Figures 2, 6a, and 7b) could indicate one or more of three possible scenarios: (1) the sedimentary layers are curved upward, (2) relatively high seismic velocities in the chimneys cause the reflections to arrive earlier than adjacent reflections and thus they appear to be curved upward (a "velocity pull-up"; e.g., Løseth et al., 2009), or (3) truncated seismic reflections at the chimney margins are smeared upward by the seismic migration operator (i.e., "migration smiles"). A conclusive answer to this question would require drilling, but we suggest that the reflection appearance is due in part to true geologic upwarping, because some full anticlinal reflections are visible and because of the apparent dip angle varies between many (though not all) of the reflections. We suggest in addition, however, that seismic migration of truncated reflections has contributed to the observed appearance, based on the regular and symmetrical appearance of some of the curves, and on the fact that some reflections from one side of the chimney features appear to cross reflections from the opposite side of the chimney. Fluid flow is the likely cause of both the upwarping and the truncated reflectors.

Our interpretation that focused flow along the chimneys has led to the observed gas hydrate in the mid-depth strata at well GC955-H suggests current or recent gas flow, an interpretation supported by the presence of the seafloor fluid expulsion feature. 
Gas may exist within the GHSZ due to pore-water salinity and/or thermal effects associated with fluid flow (e.g., Milkov et al., 2004; Liu and Flemings, 2006). Gas that migrates laterally from the chimneys in higher-permeability sediments would form gas hydrate where it encounters conditions favorable to gas hydrate stability.

The location of seafloor venting appears to have migrated over time (Figure 7), shifting north-south along the chimney features and also jumping east-west between chimneys. At the present time, only one seafloor vent feature is evident (though we cannot eliminate the possibility that greater seafloor venting has occurred in the past). Overall, the indications of fluid flow observed in our study area seem less prolific than that observed elsewhere in the world (e.g., Bünz et al., 2003; Crutchley et al., 2010; Ryu et al., 2013; Plaza-Faverola et al., 2015), indicating that the rate and volume of fluid flow at GC955 may be comparatively low. The small scale of the focused-flow features at GC955, including relative to other seafloor features observed in the Gulf of Mexico (e.g., https://www.boem.gov/Seismic-Water-Bottom-Anomalies-Map-Gallery/), combined with the lack of free gas beneath the gas hydrate in well GC955-H, may indicate a limited gas supply in this area. The present-day seafloor feature at GC955 (Figure 7a) is similar to the dome structures that have been identified elsewhere as potentially (e.g., Lee and Chough, 2002), but not necessarily (e.g., Koch et al., 2015) precursors to larger pockmark vent features. With limited gas at GC955 it is unlikely that this particular feature represents the early stages of pockmark development; 
instead it appears to be the current manifestation of a sustained seafloor seepage system.

The 2013 high-resolution seismic data provide the opportunity to evaluate possible gas and gas hydrate accumulations away from wells GC955-H and GC955-Q. These data show no major fault systems (potential fluid migration pathways) in the area of well GC955-I and thus support earlier interpretations that gas hydrate is largely absent at this location due to minimal gas charge related to the well being distant from the structurally highest part of the reservoir (Boswell et al., 2012a). The 2013 seismic data show only minor indications of gas and gas hydrate near, and south of, well GC955-I; these include strong positive-polarity reflections of limited extent, and possible indications of an additional focused fluid-flow feature. More broadly in the GC955 area, the identifiable channel features (labeled as T2, T3, and T4 in Figure 2c) show strong positive-polarity seismic reflections potentially indicating gas hydrate in the sediments at the base of the channels, possibly in coarse-grained channel lag deposits.

\subsection{Sedimentary stratigraphy and sand deposition}

The 2013 high-resolution seismic data provide an opportunity to identify sedimentary facies with greater detail within the kilometer-scale reservoir and the broader area, and potentially to refine the lithologic and stratigraphic interpretations presented by Weimer (1989), McConnell et al. (2000) Hutchinson et al. (2009) and Boswell et al. (2012a). Such detail is highly relevant to reservoir 
quality considerations including vertical and lateral connectivity. The kilometerscale seismic character of the main reservoir at GC955 (for example, in Figures 2 and 8) shows the classic "gullwing" shape that is often associated with sediments deposited in a channel/levee environment - a U-shaped channel separates highstanding levees on the margins (e.g., Clemenceau et al., 2000; Kendrick, 2000). For the case of GC955, the western "wing", at well GC955-Q, is more pronounced than its eastern counterpart.

At the tens-of-meters scale, as is provided by the high-resolution 2D data, the reflectivity patterns of the GC955 reservoir sediments strongly show a set of characteristics that typify proximal levee deposits (but are rarely imaged so clearly due to limited resolution of standard industry seismic data). This pattern is most obvious for the sediments at well GC955-Q (Figures 2, 8a, and 8b), which may be seen as a discrete package of moderately dipping semi-continuous reflections that is thickest in the center and tapers down at the edges. As illustrated in Figure 8, similar patterns are observed for all or nearly all of the sediments in the main reservoir at GCC955. Further, the thin sand/shale interlayering indicated by borehole logs is entirely consistent with deposition in a proximal levee environment, more so than with channel deposition that would be expected to deposit thicker sand layers or distal levees that would be expected to deposit broad layers generally including a greater proportion of fine-grained sediments (e.g., Brown and Slatt, 2002; Weimer and Slatt, 2006). As such, we interpret that the GC955 reservoir is composed entirely, or almost entirely, of sediments deposited as 
proximal levees and we identify the appearance seen throughout the reservoir and exhibited in Figure 8 as being one of four primary seismic facies in the GC955 study area.

During the time when levee sediments were being deposited, we infer that the channels themselves were primarily erosional features. These bypass channels carried sediments that would either be deposited in levees or carried farther downslope, and they scoured previously deposited sediments in the GC955 area. Possible direct indications of channels in the central GC955 area include a few subhorizontal surfaces (for example, those marked in Figure 8b) that may represent relict channel surfaces (but the sediments above these channel surfaces are not channel sediments). The levee sediments have been heavily impacted by erosional intervals that removed and re-deposited sediments, with the end result being a reservoir composed of many discrete "pods" of levee deposits that were deposited in numerous depositional episodes.

One possible set of pod boundaries is sketched in Figure 8 but we acknowledge that other interpretations are possible; the key point is that these are discrete bodies of predominantly proximal levee deposits. The pod at GC955-Q is one of the largest intact pods in the area (Figure 8 parts a and b), being on the order of several hundred meters across (north-south as well as east-west) and approximately $100 \mathrm{~m}$ thick. In the cross-sectional view of Figure 8a, the pod appears to represent a complete levee package, but views showing the along-channel structure (north- 
south, out of the plane of the data in Figure 8a) indicate that the rest of this particular levee has been removed by erosion. Individual reflections within the reservoir likely represent stacked sands and provide a representation of reservoir internal architecture much closer to the scale of the actual layering than can be seen in the 3D data, but coarser than the meter-scale layers seen in borehole data. Significant thickness heterogeneity in the strata above the levee deposits indicates that the levee pod at GC955-Q was a positive-relief feature at the time when channel activity shifted away from the GC955 area (although fault motion likely also contributed to the thickness variation). Other pods in the GC955 reservoir are complete to varying, and generally lesser, extents. The scale and overlapping nature of the levee deposit pods, combined with 2D seismic imaging of the complex geology, prohibit the mapping of specific channel locations and levee features through time.

We consider the pattern that we observe at GC955 to be distinct from the highamplitude reflection packets (HARPs) observed in other areas (e.g., Manley and Flood, 1988; Flood et al., 1991; Pirmez et al., 2000), in that HARPs are characterized by laterally continuous reflectors with multi-kilometer spatial extent whereas at GC955 we observe discrete packages of parallel reflections with individual extent less than a few hundred meters. Block rotation (e.g., Sawyer et al., 2007) may have contributed toward establishing the discrete pods of proximal levee material, possibly overprinting the complex sedimentary distribution created by depositional and erosional processes. 
Similar analysis of the other sediments in the area of GC955 provides a more complete understanding of the depositional environment during and after reservoir deposition, and it reveals two additional distinct seismic facies. Overlying the main reservoir is a unit of material that is generally acoustically weak (identified in Figure 6 as "low-permeability unit"); we suggest that this seismic facies represents finegrained sediments with little internal heterogeneity, deposited during times of negligible coarse-grained sediment influx. This unit exists above the levee deposits in the immediate area of GC955 and also within a few kilometers to the west and south (but not to the north and east); it indicates an abrupt change of depositional setting relative to the underlying sediments. Above the acoustically weak lowpermeability unit lies a sedimentary sequence with clear internal reflectivity that indicates parallel bedding and at least some degree of grain-size sorting; the sequence is visible between approximately 3.0 and 3.15 seconds twtt at the left edge of the plots in Figure 6a. Borehole data from wells GC955-H and GC955-Q indicate the presence of very thin ( $\mathrm{cm}$ - to $\mathrm{m}$ - scale) sand layers within primarily fine-grained sediments, and at GC955- $\mathrm{H}$ the presence of fracture-filling gas hydrate in this interval (Lee and Collett, 2012). The generally parallel character of reflections in this seismic facies, and the presence of thin layers with elevated sand occurrence, suggest shelf-slope deposition of mud-rich sediments and occasional sheet sands, likely distal levee deposits. 
Contemporaneous with the slope sediments, several kilometers to the east, channel incisions are clearly evident (Figure 2), with widths of several hundred meters. The material beneath these channel features shows seismic characteristics indicating possible mass-transport deposits presumably associated with the nearby channel activity and/or with salt uplift. The eastern channels appear to have been mainly bypass (erosional and transport) features and we suggest that the sediments filling the channels are essentially the same shelf slope deposits observed above the main reservoir at GC955. Although deposition of channel sediments was likely minimal, a thin layer of coarse-grained channel lag at the base of each channel is expected (e.g., Mayall et al., 2006) and would be consistent with the planar high-relative-seismicamplitude reflections observed within the channels (Figure 2). The origin and specific attributes of these channel-filling sediments cannot be determined from available data, however. Levee sediments are evident to the east of the channel incisions, and were presumably also deposited on the western margins of the channels but were subsequently scoured during the westward migration of channel activity.

Finally, following the period of lower slope deposition throughout the study area and intermittent channel incision to the east and north east of GC955, fine-grained deposition prevailed throughout the area and resulted in approximately one hundred meters of fine-grained sediments beneath the seafloor. This succession constitutes the fourth seismic facies, which is distinct from the deeper fine-grained interval in that some layering is indicated by the parallel-bedded reflectivity. 
Relatively high seismic amplitude can, at some burial depths and in some geologic settings, indicate grain size heterogeneity and sandy sediments due to these sediments providing strong positive impedance contrasts relative to muddy and other fine-grained sediments (e.g., Cook and Sawyer, 2015; Boswell et al., 2016). In our study area, grain-size variation surely contributes to the impedance contrasts responsible for seismic reflectivity, but we suggest that the gas and gas hydrate distribution (discussed in section 4.2) is a major contributor to broad-scale seismic amplitude heterogeneity such as the high-seismic amplitude of the main reservoir (Figure 2).

\subsection{Geologic evolution}

Combined analysis of the high-resolution 2D seismic data, the industry 3D data, and the LWD data allows us to determine relative timing for the major events shaping the present-day geology at GC955, and this is presented visually in Figure 9. Finegrained sedimentary deposition dominated the geologic history at GC955 during most of the late Pliocene through Pleistocene stages of the Mississippi Fan development, with coarser-grained material largely being deposited 100 to $200 \mathrm{~km}$ east (Weimer, 1989). A period of channel activity then occurred at and near GC955, resulting in deposition of most of the sediments of interest in our gas hydrate studies in the area (Weimer's channel 12g). The relevant activity began with channel/levee depositional and erosional processes directly at GC955, resulting in accumulation of the proximal levee deposits that make up the main gas hydrate 
reservoir discussed in section 4.3. Around this same time, salt-driven uplift commenced, with an oblong salt structure directly beneath GC955 (expressed in the bathymetry as noted in Figure 1, and discussed by McConnell et al., 2010).

The salt-driven uplift at GC955 caused the main channel activity (initially at the position of notation "T1" in Figure 2c) to avulse eastward by a few kilometers, with the channel adjusting course in response to the uplift at GC955 and the second saltdriven uplift at Green Knoll approximately $10 \mathrm{~km}$ to the northeast. Accordingly, fine-grained deposition dominated at GC955, with a small sand fraction that increased as the eastern channel gradually shifted back westward. The eastern channel activity left behind the distinct channel incisions discussed in section 4.3. Channel activity gradually shifted westward (as indicated by designations T2, T3, and T4 in Figure 2c) and continued to the time of the broad unconformity identified earlier (an interpretation based on the visual identification of channel deposits in images such as that shown in Figure 2b). The unconformity represents a period of widespread erosion, presumably due to a combination of continued structural uplift and sea level drop, and it was followed by primarily fine-grained deposition to the present day. Debris flow material is visible to the west of the GC955 area (Figures 2 and 4) indicating mass transport processes during this time, possibly also related to bathymetry shifting in response to salt uplift.

Uplift of salt beneath GC955 has continued until the present day, or close to it, an interpretation based on the fact that sedimentary layers up to the most recent (i.e., 
shallowest) are thicker in areas adjacent to the main GC955 area than they are above the uplifted dome. Associated with this uplift, a prominent east-west oriented crestal graben feature developed in the sediments overlying the salt structure as described earlier and shown in Figure 5. The graben likely formed in response to the salt-driven uplift, but exact timing of the onset of faulting is uncertain. The graben faults extend upward only to the depth of the unconformity, indicating that this faulting ceased at the time of the unconformity.

The presence of organic material and microorganisms could have resulted in the production of microbial gas within all sediments as they were deposited (e.g., Frye, 2008), a possibility that is indicted by the lightly dashed line in Figure 9. The migration of thermogenic gas from deeper in the sedimentary section was possible as soon as such gas was available and as soon as suitable migration pathways existed. Major regional source rocks are likely Jurassic (Hood et al., 2002). Thermal maturity is less well constrained but was likely attained at least within the last 5 m.y. (Cole et al., 2001). The large-throw faulting associated with extension and crestal graben development on the main domed structure at GC955 provides a network of migration pathways, and we suggest that the upward flow of gas and thus gas charge to the main GC955 reservoir commenced between the inception of extensional faulting and the time of the unconformity. The relict seafloor seepage feature (Figures 6a and 7b) indicates that gas was present in the main reservoir at the time of the unconformity and that focused fluid flow had begun by that time. This focused fluid flow may have begun in response to stress changes associated 
with the cessation of graben activity and/or the erosion of seafloor material but this is uncertain. The present-day seafloor vent indicates that focused gas flow is still occurring today or at least that it has occurred recently.

\section{Gas hydrate reservoirs at GC955}

\subsection{Gas hydrate volume estimation}

The 2013 high-resolution seismic dataset provides an opportunity to estimate the volume of gas hydrate present at GC955, complementing earlier estimates (e.g., Boswell et al., 2012b). We focus on the main reservoir body for this estimation, because it is assumed to contain the majority of gas hydrate in the area and because it represents the most promising reservoir. Our gas hydrate volume calculation approach is based on an estimated volume for the entire reservoir body and estimated bulk properties for the reservoir. We assume that the reservoir characteristics are broadly homogenous throughout the area of interest, an assumption that is consistent with our interpretation that the reservoir sediments were entirely or almost entirely deposited as proximal levee material.

We mapped a three-dimensional surface representing the top of the main reservoir body, starting with arrival-time picking in all of the 2D seismic transects that cross the relevant area. For locations where intersecting transects indicate different arrival times due to out-of-plane reflections, we estimated a best arrival time based on the assumption that transects in the dip direction will include minimal out-ofplane reflection energy. The 2D data provided a dense grid of arrival times, and 
from this we calculated a complete top-of-reservoir surface via interpolation and extension, followed by minor smoothing with median filtering ( 80 x $80 \mathrm{~m}$ filter).

The exact depth of the BGHS is uncertain in the GC955 area, as no clear bottomsimulating reflectors or other seismic indicators exist with any of the available seismic datasets. The contact between gas hydrate and free gas is best constrained (though still somewhat uncertain) at the GC955-Q well. At GC955-Q, LWD data indicate gas-hydrate-bearing strata at the deepest LWD measurement points and other drilling observations indicate free gas within the borehole (potentially due to flow enabled by fracturing ahead of the drill bit) as described by Collett et al. (2010) and Boswell et al. (2012a). We calculated a BGHS surface by picking the seafloor arrival time in the 3D seismic data and shifting this surface downward to a position immediately below the lowest recorded LWD data in the GC955-Q well (Figure 10). This represents the shallowest possible depth to the BGHS at this location, and thus our gas hydrate volume estimate can be regarded as a minimum value. Geologic heterogeneity and evidence of fluid flow in the area suggest that the BGHS could be quite heterogeneous at GC955, but in the absence of firm data constraints on BGHS complexity we consider the simple downshifted seafloor to be a reasonable and best-available approximation.

We estimated the volume of main reservoir body that lies within the BGHS by calculating the volume between the top-of-reservoir and BGHS surfaces based on a seismic velocity of $2500 \mathrm{~m} / \mathrm{s}$ (estimated from the LWD data, Figure 11). Assuming 
that $50 \%$ of this total volume represents viable gas hydrate reservoir (due reservoir quality variation potentially prohibiting gas hydrate formation, based on the hydrate distribution observed at well GC955-H by Boswell et al., 2012b), 40\% porosity within the gas hydrate reservoir, and $80 \%$ gas hydrate saturation of that porosity, we estimate approximately $4 \times 10^{6} \mathrm{~m}^{3}$ of gas hydrate within the main reservoir body. A volumetric yield factor of 1:164 suggests that this is equivalent to a total in-place gas volume of $6.6 \times 10^{8} \mathrm{~m}^{3}$ of gas. Using a different approach for the reservoir volume estimation, Boswell et al. (2012b) estimated $5.5 \times 10^{8} \mathrm{~m}^{3} \mathrm{in}$-place gas in the specific accumulations penetrated by wells GC955-H and GC955-Q. The similarity between these estimates is reassuring, and the fact that our estimate is somewhat larger is reasonable given that our aim was to include the entire reservoir. It is important to note that these estimates include only gas hydrate, and that considerable free gas may be present in the portion of the reservoir body that is below the BGHS.

\subsection{Reservoir characterization and connectivity}

When considering the gas hydrate resource potential at GC955, reservoir heterogeneity and connectivity are at least as important as the total in-place volume of gas as they will have a critical effect on any efforts to develop this resource. The improved understanding of depositional setting described in the previous sections provides an opportunity to consider the potential implications for reservoir characteristics. Key factors impacting broad reservoir continuity include the degree of hydrologic communication between sands in a given levee deposit, the spatial 
extent of individual levee deposit pods, the communication between adjacent levee deposit pods, and the degree to which the overall reservoir may be further compartmentalized by faulting.

Connectivity and other reservoir properties within individual proximal levee deposit pods are impacted by the interlayering of thin shale and sand layers and the correspondingly lower ratios of net sand to total sediment thickness that typify levee reservoirs as compared with typical channel sand reservoirs (Mayall and Stewart, 2000). Gamma ray logs and other LWD from the GC955 wells (Figure 11) show meter-scale layering, though layering may be undersampled by these measurements. The vertical measurement interval is $0.15 \mathrm{~m}$, but any given measurement represents the spatial average of properties surrounding the measurement point; the scale of this vertical smearing is variable and difficult to estimate with confidence. Further complicating reservoir quality estimation, the thin strata deposited in these settings are often interrupted by an abundance of subseismic scale erosional and depositional features including mud layers (Browne and Slatt, 2000). The presence of thin mud layers may be expected to reduce reservoir performance (e.g., Browne and Slatt, 2000), but during production, lateral connectivity within a levee reservoir has been observed to be quite good even over a wide area (Clemenceau et al., 2000; Bramlett and Craig, 2002). Further, for gas hydrate production, the presence of clay layers has been suggested as potentially improving reservoir performance due to their impact on thermal transmission properties (Myshakin et al., 2012). Vertical connectivity within an individual levee 
is expected to be variable and overall poorer than lateral connectivity, but it too can be surprisingly good because the bedding disruption provided by small-scale features such as micro-scours and slumps may be beneficial to flow (Clemenceau et al., 2000), and because turbidite shales often exhibit relatively high porosity and brittleness as compared with pelagic shales (Dribus, 2014). Further, reservoir performance in levee reservoirs has been seen to improve over time, possibly due to the breakdown of internal flow restrictions during the production process (Bramlett and Craig, 2002). The spatial scale of identifiable levee deposit pods is on the order of hundreds of meters (Figure 8), although in other areas the absence of identifiable pods likely suggests smaller individual features. The levee deposit pod at well GC955-Q is the largest that can be readily identified, possibly extending five hundred meters laterally and $100 \mathrm{~m}$ vertically.

Broader reservoir connectivity is related to stratigraphic and structural factors influencing communication between levee pods. The scale of discrete pods indicates that these are incomplete levees thus that erosional processes played a significant role between depositional episodes. However, this does not preclude the possibility that fine-grained material, possibly pelagic, may have been draped over individual levee deposit pods (e.g., Browne and Slatt, 2000). Even a very thin pelagic shale layer can substantially impede fluid flow and the presence or absence of such layers cannot be conclusively determined with the available data. 
In addition to stratigraphic considerations, the main GC955 reservoir is cut by faulting that likely impacts reservoir communications (Boswell et al., 2012b), and this may include block rotation activity (Sawyer et al., 2007). Restricted broad-scale reservoir continuity is indicated by the heterogeneous pore-fluid distribution that is seen in borehole data. Reservoir heterogeneity, and perhaps compartmentalization, is also indicated by the discrete zones of high seismic reflection amplitude observed in 3D seismic data (Boswell et al., 2012a). Analysis of the 2D seismic data suggests that these high-seismic-amplitude areas correspond at least roughly with individual pods of proximal levee material and thus that depositional characteristics provide at least some control on fluids in the reservoir.

The nature of the transition between the top of the main reservoir and the overlying fine-grained sediment is of interest due to its relation with the evolution of the fluid system at GC955 and also because it may provide insight regarding gas hydrate reservoirs in other areas. A seal on the reservoir is indicated by the presence of gas and gas hydrate in the reservoir and by the absence of gas and gas hydrate in the upper layers, other than where large-throw normal faults intersect the top of the reservoir. It is noteworthy that borehole resistivity data in well GC955-H (Figure 11) indicate an abrupt vertical transition between water-saturated and gas-hydratesaturated sediments at the top of the main reservoir (at approximately $2460 \mathrm{~m}$ depth) whereas gamma ray data suggest that sediment composition grades from mud-dominated to sand-dominated over a vertical span of approximately $30 \mathrm{~m}$ (Figure 11). A similar pattern is observed at well GC955-Q, although the resistivity 
data appear somewhat more transitional, suggesting a 1- to 3-m gradient from water-saturated to gas-hydrate saturated sediments. For comparison, Figure 11 includes plots of $V_{\text {shale }}$ as calculated from gamma ray logs using standard techniques (Asquith and Krygowski, 2004) and minimum and maximum gamma values of 25 and $80 \mathrm{API}$ as indicated on the plots. Gamma logs (and other LWD data) must be considered carefully in zones where borehole washout has occurred. In particular, for well GC955-H the caliper data show a zone of extensive washout in the depth range from 2435 to $2460 \mathrm{~m}$, and call into question the gamma log data in this interval, which happens to correspond with the top of the reservoir. An arbitrary, and perhaps optimistic, estimate is that the gamma ray data are robust where the true borehole diameter is within a half inch of the nominal borehole diameter (8.5 inches, for the LWD data at GC955) and gamma values where the washout is greater than a half inch are marked with dark blue dots in Figure 11. The remaining gamma values around $2450 \mathrm{~m}$ depth are sparse, and must be interpreted with caution, but they do indicate a gradational boundary at the top of the reservoir.

The seismic data provide further insight regarding this boundary. In the industry 3D seismic data, the top of the reservoir at the locations of GC955-H and GC955-Q appears as a strong positive-polarity reflection, indicating that at the scale of that seismic wavelength (approximately $50 \mathrm{~m}$, for a $35-\mathrm{Hz}$ wave traveling at $1700 \mathrm{~m} / \mathrm{s}$ ) the boundary is a sharp, increasing-impedance, interface. In contrast, the 2D seismic data show a weaker positive reflection at the top of the reservoir, potentially indicating that seismic waves of this wavelength (approximately $15 \mathrm{~m}$, based on a 
$115-\mathrm{Hz}$ wave traveling at $1700 \mathrm{~m} / \mathrm{s}$ ) "see" the boundary as a gradational impedance increase rather than as a sharp interface. If we assume that the seismic reflections correspond with reservoir characteristics, then these qualitative seismic observations are consistent with LWD indications that the top of the reservoir is gradational over a scale of approximately $30 \mathrm{~m}$, and thus that the occurrence of gas hydrate (which shows a spatially abrupt upper surface) is controlled by subtle reservoir property variations (as inferred for this area by Boswell et al., 2012b). The seismic reflections may be expected to correspond predominantly with the top of gas hydrate saturation, however, and in this case an explanation for the observed 2D-vs-3D contrast is less evident. Further, the sonic log data (Figure 11) indicate a sharp velocity contrast at the top of the gas-hydrate-saturated zone; this would be expected to result in a strong positive-polarity reflection for both the 3D and the 2D seismic data.

Inferences of grain size controlling gas hydrate occurrence meshes with similar interpretations from elsewhere around the world (e.g., Torres et al., 2008; Collett et al., 2009; Boswell et al., 2015). Borehole washout seems to occur where sandy sediments exist but where reservoir characteristics are inadequate for gas hydrate formation and thus the hydrate-free sediment matrix is weak.

Information constraining reservoir characteristics and controls on hydrate occurrence at the bottom of the reservoir is sparse. Well GC955-Q did not reach the bottom of the reservoir, and seismic penetration into the lower parts of the 
reservoir is limited in both the 3D and 2D seismic datasets due to the strong impedance contrasts (and resulting reduced energy transmission) near the top of the reservoir. LWD data for well GC955-H (Figure 11) do extend below the base of gas-hydrate-containing sediments, however, and resistivity data indicate a vertically abrupt (but layered) transition from gas-hydrate-bearing sediments to waterbearing sediments in a zone where gamma data show no apparent loss of reservoir quality (though the gamma data may again be questionable due to borehole washout). This suggests that reservoir quality is not a critical control on the presence of gas hydrate here and that other factors need to be considered. One obvious possibility is that the system may be undercharged with gas, and this is consistent with the absence of gas beneath the gas-hydrate-bearing strata (even a small amount of free gas would be evident as a low velocity zone in the sonic log). The gas hydrate fluid flow pathways described earlier in this paper provide an escape mechanism for gas in the area of well GC955-H (but not at GC955-Q). Additionally, the lack of free gas at the base of well GC955-H indicates that deeper gas has not replaced gas that migrated upward, and the scale of focused fluid flow pathways in the GC955 area (less pronounced than has been observed elsewhere in the world) further supports the inference that the GC955 system is less gas charged than systems elsewhere.

\section{Conclusions}


High-resolution seismic data acquired in 2013, combined with industry 3D seismic data and 2009 LWD data, provide an improved understanding of the geologic evolution of the GC955 area. Based on these data, we interpret that the main gas hydrate reservoir is an assemblage of sand-rich proximal levee deposits deposited in a primarily erosional channel/levee system. Salt uplift beneath the area of GC955 caused eastward channel avulsion, followed by a period of bypass channel flow that left behind several distinct channel incisions likely filled with dominantly finegrained sediments. Salt uplift also resulted in doming of the sediments at GC955, which led to creation of a crestal graben and associated normal faults and caused the main GC955 gas hydrate reservoir to be domed upward into a four-way closure structure.

Inferences from analysis of all available data suggest that fluid flow, and the gas and gas hydrate distribution, at GC955 are controlled by a complex combination of structural and stratigraphic features. Focused fluid-flow pathways between the main gas/hydrate reservoir and the seafloor are distinct from other areas in the world in that their scale appears generally smaller, and at the seismic scale their shape appears planar (length up to approximately $600 \mathrm{~m}$ ) rather than columnar. The pathway of current, or recent, fluid flow is essentially a point source at the seafloor, however, indicating that fluid flow is occurring along only a small portion of the planar pathway. This observation may indicate generally lower volumes of gas migration in the GC955 system than in other areas, but this cannot be stated with certainty based on available data. 
Our high-resolution 2D seismic data allow refinement of conceptual models for the main reservoir at GC955, and we suggest that stratigraphic features (discrete levee "pods") play a role in reservoir compartmentalization. The properties of proximal levee reservoirs are complex. However, based on reservoir performance observed at similar reservoirs elsewhere in the Gulf of Mexico, we suggest that reservoir continuity may be good in a lateral direction and at least adequate vertically, within individual levee deposit pods (each up to a few hundred meters across).

Inferences from the high-resolution 2D data support earlier interpretations that the presence of gas hydrate within the sand-rich levee reservoir sediments appears to be controlled at least partially by reservoir quality, with gas hydrate saturation showing an abrupt upper surface within a gradational upper reservoir boundary. We estimated the in-place volume of gas hydrate within the main reservoir body as corresponding with a total of $6.6 \times 10^{8} \mathrm{~m}^{3}$ of gas. The depth to the base of gas hydrate stability (BGHS) is uncertain, however, and it is likely heterogeneous due to localized fluid flow. Similarly, the available data (mainly the LWD data) indicate a heterogeneous fluid distribution beneath the BGHS. The presence of a watersaturated sand reservoir below gas-hydrate saturated layers at GC955-H suggests the possibility that the system is not fully gas charged.

\section{Acknowledgments}


We thank Carolyn Ruppel for her many contributions to this research program, including extensive efforts that enabled the 2013 data acquisition program. We thank all those who contributed to the data acquisition, including the shipboard scientific party and the crew of the $R / V$ Pelican. We thank

WesternGeco/Schlumberger for permission to publish images from their 3D seismic volume. We appreciate thoughtful reviews provided by Gareth Crutchley, Dan McConnell, and Jared Kluesner; these have improved the content and writing of this paper. Funding: data acquisition was made possible by support from the U.S. Department of Energy, the U.S. Bureau of Ocean Energy Management, and the U.S. Geological Survey.

\section{References}

Asquith, G.B., Krygowski, D. and Gibson, C.R., 2004. Basic well log analysis (Vol. 16). Tulsa, OK: American Association of Petroleum Geologists.

Boswell, R. and Collett, T.S., 2011. Current perspectives on gas hydrate resources. Energy \& Environmental Science, 4(4), 1206-1215.

Boswell, R., Collett, T.S., Frye, M., Shedd, W., McConnell, D.R., and Shelander, D., 2012a. Subsurface gas hydrates in the northern Gulf of Mexico. Marine and Petroleum Geology, 34, 4-30. 
Boswell, R., Frye, M., Shelander, D., Shedd, W., McConnell, D., and Cook, A. 2012b. Architecture of gas-hydrate-bearing sands from Walker Ridge 313, Green Canyon 955, and Alaminos Canyon 21: Northern deepwater Gulf of Mexico. Marine and Petroleum Geology, 34: 134-149.

Boswell, R., Yamamoto, K., Lee, S.R., Collett, T., Kumar P., and Dallimore, S., Chapter 8 - Methane Hydrates, In Future Energy (Second Edition), edited by Trevor M. Letcher,, Elsevier, Boston, 2014, Pages 159-178, ISBN 9780080994246, http://dx.doi.org/10.1016/B978-0-08-099424-6.00008-9.

Boswell, R., Shipp, C., Reichel, T., Shelander, D., Saeki, T., Frye, M., Shedd, W., Collett, T., and McConnell, D., (2016). Prospecting for marine gas hydrate resources. Interpretation, 4(1), SA13-SA24, doi: 10.1190/INT-2015-0036.1.

Bramlett, K.W. and Craig, P.A., 2002. Core characterization of slope-channel and channel-levee reservoirs in Ram Powell field, Gulf of Mexico. In Deep-water core workshop, northern Gulf of Mexico: Gulf Coast Section SEPM Foundation, 1-18.

Browne, G.H. and Slatt, R.M., 2002. Outcrop and behind-outcrop characterization of a late Miocene slope fan system, Mt. Messenger Formation, New Zealand. AAPG Bulletin, 86(5), 841-862. 
Bünz, S., Mienert, J. and Berndt, C., 2003. Geological controls on the Storegga gashydrate system of the mid-Norwegian continental margin. Earth and Planetary Science Letters, 209(3), 291-307.

Collett, T.S., Johnson, A.H., Knapp, C.C. and Boswell, R., 2009. Natural gas hydrates: a review. In: Collett, T. et al. (Eds.), Natural Gas Hydrates - Energy Resource Potential and Associated Geologic Hazards. AAPG Memoir 89, p. 74.

Collett, T., Boswell, R., Frye, M., Shedd, W., Godfriaux, P., Dufrene, R., McConnell, D., Mroszewski, S., Guerin, G., Cook, A., Jones, E., Roy, R., 2010, Gulf of Mexico Gas Hydrate Joint Industry Project Leg II: Operational Summary, National Energy Technology Laboratory, 27 p, http://www.netl.doe.gov/File Library/Research/OilGas/methane hydrates/OpSum.pdf.

Collett, T.S., Lee, M.W., Zyrianova, M.V., Mrozewski, S.A., Guerin, G., Cook, A.E., and Goldberg, D.S. 2012, Gulf of Mexico Gas Hydrate Joint Industry Project Leg II loggingwhile-drilling data acquisition and analysis. Marine and Petroleum Geology, 34, 4161.

Clemenceau, G.R., Colbert, J. and Edens, D., 2000. Production results from leveeoverbank turbidite sands at Ram/Powell field, deepwater Gulf of Mexico. In DeepWater Reservoirs of the World, GCSSEPM Foundation 20th Annual Research Conference, 241-251. 
Cole, G.A., Yu, A., Peel, F., Taylor, C., Requejo, R., DeVay, J., Brooks, J., Bernard, B., Zumberge, J. and Brown, S., 2001. The deep water Gulf of Mexico petroleum system: Insights from piston coring, defining seepage, anomalies and background, In GCSSEPM Foundation 21 ${ }^{\text {st }}$ Annual Research Conference, Petroleum Systems of Deep-Water Basins.

Cook, A.E., Anderson, B.I., Rasmus, J., Sun, K., Li, Q., Collett, T.S. and Goldberg, D.S., 2012. Electrical anisotropy of gas hydrate-bearing sand reservoirs in the Gulf of Mexico. Marine and Petroleum Geology, 34(1), 72-84.

Cook, A.E. and Sawyer, D.E., 2015, The mud-sand crossover on marine seismic data. Geophysics, 80(6), A109-A114. doi: 10.1190/geo2015-0291.1.

Crutchley, G.J., Pecher, I.A., Gorman, A.R., Henrys, S.A. and Greinert, J., 2010. Seismic imaging of gas conduits beneath seafloor seep sites in a shallow marine gas hydrate province, Hikurangi Margin, New Zealand. Marine Geology, 272(1), 114-126.

Dribus, J. R., 2014, Consideration of the origin and characteristics of tubidite sediments, Petrophysics, 55, 2, 88-95.

Flood, R.D., Manley, P.L., Kowsmann, R.O., Appi, C.J. and Pirmez, C., 1991. Seismic facies and late Quaternary growth of Amazone submarine fan. In: P. Weimer and 
M.H. Link (Editors), Seismic facies and sedimentary processes of submarine fans and turbidite systems. Springer-Verlag, New York, pp. 415-433.

Frye, M., 2008, Preliminary Evaluation of In-Place Gas Hydrate Resources: Gulf of Mexico Outer Continental Shelf, Minerals Management Service report 2008-004, 136 p., http://www.boem.gov/uploadedFiles/BOEM/Oil_and_Gas_Energy_Program/Resour ce_Evaluation/Gas_Hydrates/MMS2008-004.pdf.

Haines, S.S., Hart, P.E., Ruppel, C.D., O’Brien, T., Baldwin, W., White, J., Moore, E., Dal Ferro, P., and Lemmond, P., 2014, Cruise report for P1-13-LA, U.S. Geological Survey gas hydrates research cruise, R/V Pelican April 18 to May 3, 2013, deepwater Gulf of Mexico: U.S. Geological Survey Open-File Report 2014-1080, 33 p., http://dx.doi.org/10.3133/ofr20141080.

Haines, S.S., Hart, P., Shedd, W., and Frye, M., 2014, Seismic Investigation of Gas Hydrates in the Gulf of Mexico: 2013 Multicomponent and High-Resolution 2D Acquisition at GC955 and WR313: Proceedings of the Offshore Technology Conference, May 5-8, 2014, Houston, Texas, 15 p. doi:10.4043/25318-MS. https://www.onepetro.org/conference-paper/OTC-25318-MS

Heggland, R., 2004. Definition of geohazards in exploration 3-D seismic data using attributes and neural-network analysis. AAPG bulletin, 88(6), 857-868. 
Hood, K. C., L. M. Wenger, O. P. Gross, and S. C. Harrison, 2002, Hydrocarbon systems analysis of the northern Gulf of Mexico: Delineation of hydrocarbon migration pathways using seeps and seismic imaging, in Surface exploration case histories: Applications of geochemistry, magnetics, and remote sensing, D. Schumacher and L. A. LeSchack, eds., AAPG Studies in Geology No. 48 and SEG Geophysical References Series No. 11, 25-40.

Hutchinson, D., Boswell, R., Collett, T.S., Dai, J., Dugan, B., Frye, M., Jones, E., McConnell, D., Rose, K., Ruppel, C., Shedd, W., Shelander, D., Wood, W., 2009. Gulf of Mexico Gas Hydrate Joint Industry Project Leg II: Green Canyon 955 Site Selection. Proceedings of the Drilling and Scientific Results of the 2009 Gulf of Mexico Gas Hydrate Joint Industry Project Leg II. http://www.netl.doe.gov/File Library/Research/Oil-Gas/methane hydrates/GC955SiteSelect.pdf.

Hutchinson, D.R., Ruppel, C.D., Roberts, H.H., Carney, R.S. and Smith, M., 2011. Gas hydrates in the Gulf of Mexico. In C. Holmes (ed.), Gulf of Mexico Origin, Waters, and Biota: Texas A\&M University Press.

Jones, E., Latham, T., McConnell, D.R., Frye, M., Hunt, J., Shedd, W., Shelander, D., Boswell, R., Rose, K., Ruppel, C. and Hutchinson, D.R., 2008. Scientific objectives of the Gulf of Mexico gas hydrate JIP Leg II drilling. In Offshore Technology Conference. Offshore Technology Conference. 
Judd, A., and Hovland, M., 2007, Seabed Fluid Flow Impact of geology, biology and the marine environment, Cambridge University Press, 408 pgs.

Kendrick, J. W., 2000. Turbidite reservoir architecture in the northern Gulf of Mexico deepwater: Insights from the development of Auger, Tahoe and Ram/Powell Fields. In Deep-Water Reservoirs of the World, GCSSEPM Foundation 20th Annual Research Conference, 400-418.

Koch, S., Berndt, C., Bialas, J., Haeckel, M., Crutchley, G., Papenberg, C., Klaeschen, D. and Greinert, J., 2015. Gas-controlled seafloor doming. Geology, 43(7), 571-574.

Kvenvolden, K.A., 1993. Gas hydrates-geological perspective and global change. Reviews of Geophysics, 31, pp.173-187.

Lee, S.H. and Chough, S.K., 2002. Distribution and origin of shallow gas in deep-sea sediments of the Ulleung Basin, East Sea (Sea of Japan). Geo-Marine Letters, 22(4), 204-209.

Lee, M. W., Collett, T., 2012, Pore- and fracture-filling gas hydrate reservoirs in the Gulf of Mexico Gas Hydrate Joint Industry Project Leg II Green Canyon 955 H well, Marine and Petroleum Geology, 2012: 34, 62-71. 
Liu, X. and Flemings, P.B., 2006. Passing gas through the hydrate stability zone at southern Hydrate Ridge, offshore Oregon. Earth and Planetary Science Letters, 241(1), 211-226.

Løseth, H., Gading, M., Wensaas, L., 2009, Hydrocarbon leakage interpreted on seismic data, Marine and Petroleum Geology, 26(7), 1304-1319.

Manley, P.L. and Flood, R.D., 1988, Cyclic sediment deposition within Amazon deepsea fan, AAPG Bulletin, 72(8), 912-925.

Mayall, M. and Stewart, I., 2000. The architecture of turbidite slope channels. In Deep-Water Reservoirs of the World: SEPM, Gulf Coast Section, 20th Annual Research Conference, 578-586.

Mayall, M., Jones, E. and Casey, M., 2006. Turbidite channel reservoirs-Key elements in facies prediction and effective development. Marine and Petroleum Geology, 23(8), 821-841.

McConnell, D.R., 2000, January. Optimizing deepwater well locations to reduce the risk of shallow-water-flow using high-resolution 2D and 3D seismic data. In Offshore Technology Conference. Offshore Technology Conference. 
McConnell, D.R., Collett, T.S., Boswell, R., Frye, M., Shedd, W.W., Dufrene, R.S., Godfriaux, P.D., Mrozewski, S., Guerin, G., Cook, A. and Jones, E., 2010, January. Gulf of Mexico Gas Hydrate Joint Industry Project Leg II: Initial Results from the Green Canyon 955 Site. In Offshore Technology Conference. Offshore Technology Conference.

McConnell, D.R., Zhang, Z. and Boswell, R., 2012. Review of progress in evaluating gas hydrate drilling hazards. Marine and Petroleum Geology, 34(1), 209-223.

Miller, J.J., Agena, W.F., Haines, S.S., and Hart, P.E., 2016, Processing of multichannel seismic reflection data acquired in 2013 for seismic investigations of gas hydrates in the Gulf of Mexico: U.S. Geological Survey Open-File Report 2016-1037, 32 p., http://dx.doi.org/10.3133/ofr20161037.

Milkov, A.V., Dickens, G.R., Claypool, G.E., Lee, Y.J., Borowski, W.S., Torres, M.E., Xu, W., Tomaru, H., Tréhu, A.M. and Schultheiss, P., 2004. Co-existence of gas hydrate, free gas, and brine within the regional gas hydrate stability zone at Hydrate Ridge (Oregon margin): evidence from prolonged degassing of a pressurized core. Earth and Planetary Science Letters, 222(3), 829-843.

Myshakin, E.M., Gaddipati, M., Rose, K. and Anderson, B.J., 2012. Numerical simulations of depressurization-induced gas production from gas hydrate reservoirs 
at the Walker Ridge 313 site, northern Gulf of Mexico. Marine and Petroleum Geology, 34(1), p.169-185.

Plaza-Faverola, A., Bünz, S., Johnson, J.E., Chand, S., Knies, J., Mienert, J. and Franek, P., 2015. Role of tectonic stress in seepage evolution along the gas hydrate - charged Vestnesa Ridge, Fram Strait. Geophysical Research Letters, 42(3), 733-742.

Paull, C.K., Ussler, W. III, and Borowaki, W.S., 1994, Sources of biogenic methane to form marine gas hydrates -- In-situ production or upward migration, in Sloan, E.D. Jr., Happel, J., and Hnatow, M.A., eds., International Conference on Natural Gas Hydrates: Annals of the New York Academy of Sciences, v. 715, p. 392-409.

Pirmez, C., Beaubouef, R.T., Friedmann, S.J. and Mohrig, D.C., 2000. Equilibrium profile and baselevel in submarine channels; examples from late Pleistocene systems and implications for the architecture of deepwater reservoirs. In: P. Weimer et al. (Editors), Deep water reservoirs of the world. GCSSEPM Foundation, Houston, pp. 782-805.

Ruppel, C., Boswell, R. and Jones, E., 2008. Scientific results from Gulf of Mexico gas hydrates Joint Industry Project Leg 1 drilling: introduction and overview. Marine and Petroleum Geology, 25(9), 819-829. 
Ryu, B.J., Collett, T.S., Riedel, M., Kim, G.Y., Chun, J.H., Bahk, J.J., Lee, J.Y., Kim, J.H. and Yoo, D.G., 2013. Scientific results of the second gas hydrate drilling expedition in the Ulleung basin (UBGH2). Marine and Petroleum Geology, 47, 1-20.

Sawyer, D.E., Flemings, P.B., Shipp, R.C. and Winker, C.D., 2007. Seismic geomorphology, lithology, and evolution of the late Pleistocene Mars-Ursa turbidite region, Mississippi Canyon area, northern Gulf of Mexico. AAPG bulletin, 91(2), pp.215-234.

Shedd, W., Boswell, R., Frye, M., Godfriaux, P., and Kramer, K. 2012. Occurrence and nature of "bottom simulating reflectors" in the northern Gulf of Mexico. Marine and Petroleum Geology 34 (1): 31-40.

Shelander, D., Dai, J. and Bunge, G., 2010. Predicting saturation of gas hydrates using pre-stack seismic data, Gulf of Mexico. Marine Geophysical Researches, 31(1-2), 3957.

Shelander, D., Dai, J., Bunge, G., Singh, S., Eissa, M. and Fisher, K., 2012. Estimating saturation of gas hydrates using conventional 3D seismic data, Gulf of Mexico Joint Industry Project Leg II. Marine and Petroleum Geology, 34(1), 96-110.

Torres, M.E., Tréhu, A.M., Cespedes, N., Kastner, M., Wortmann, U.G., Kim, J.H., Long, P., Malinverno, A., Pohlman, J.W., Riedel, M., and Collett, T.S., 2008, Methane hydrate 
formation in turbidite sediments of northern Cascadia, IODP Expedition 311: Earth and Planetary Science Letters, v. 271, p. 170-180.

Weimer, P., 1989, Sequence stratigraphy of the Mississippi Fan (Plio-Pleistocene), Gulf of Mexico, Geo-Marine Letters, 9, 185-272.

Weimer, P. and Dixon, B.T., 1994. Regional sequence stratigraphic setting of the Mississippi Fan complex, northern deep Gulf of Mexico: Implications for evolution of the northern Gulf basin margin. In Submarine fans and turbidite systems: Sequence stratigraphy, reservoir architecture and production characteristics, GCSEPM Foundation 15th Annual Research Conference, 373-381).

Weimer, P., and R. M. Slatt, 2006, Introduction to the petroleum geology of deepwater settings: AAPG Studies in Geology 57, 846 p.

Zhang, Z., McConnell, D.R. and Han, D.H., 2012. Rock physics-based seismic trace analysis of unconsolidated sediments containing gas hydrate and free gas in Green Canyon 955, Northern Gulf of Mexico. Marine and Petroleum Geology, 34(1), 119133.

\section{List of Figures}


Figure 1: Map of the Green Canyon 955 study area showing 2D seismic survey lines and the three JIP LWD boreholes drilled in 2012. The full 2013 seismic survey layout is plotted as purple lines and the transects that are shown in this contribution are plotted as light blue lines. Inset map shows location within the Gulf of Mexico, as well as other areas studied by the Gulf of Mexico Gas Hydrate Joint Industry Project.

Figure 2: (a) Image extracted from the industry 3D seismic dataset, with relevant features marked, including JIP LWD boreholes GC955-Q and GC955-H, the main reservoir body, and the underlying salt feature that caused some of the structural deformation in the area. The dashed pink line indicates the horizon that is shown in Figure 5. Gamma ray (left) and resistivity (right) well logs are shown along the well bores. (b) High-resolution 2D image along the same transect, 2D line 321, showing similar features but at higher resolution and with less depth penetration. (c) 2D seismic data with geologic interpretations. Proprietary 3D data courtesy of WesternGeco/Schlumberger.

Figure 3. Detail from seismic line 321 (a), showing the unconformity and some of the small-throw north-south-oriented faults, as indicated on the annotated plot (b). Location of the data is indicated on Figure 2.

Figure 4. Detail from seismic line 321 in part (a), with annotated plot (b) showing debris flow material that has moved from up-slope. Location of the data is indicated on Figure 2. 
Figure 5: Two oblique views of the GC955 study area. In both parts of the figure, the colored surface is picked from the industry 3D data (proprietary data courtesy of WesternGeco/Schlumberger) and its position is indicated in Figure 2. Blue lines indicate the positions of the JIP LWD boreholes, and to help visualization in this perspective view, these lines are extended to the depth of the picked surface. In (a), 2D seismic line 119 is shown down to its intersection with the surface, and in (b) 2D seismic line $155 \mathrm{a}$ is shown. The down-dropped graben is labeled in both plots, with dashed lines indicating the bounding faults on the 2D seismic data and dotted lines indicating the positions of these faults on the 3D surface. Two-way seismic travel time (twtt) is marked on each seismic section.

Figure 6: Three intersecting 2D seismic lines, illustrating key elements of the gas migration system at GC955. Line 225a (a) shows prominent chimney features just west of well GC955-H, indicating a gas source for the gas hydrate observed around depths between 3.0 and 3.1 seconds in that well. North-south lines 127c (b) and 155a (c ) reveal key distinctions between the areas of the two wells. The major (marked) faults allow gas flow (indicated by red arrows) through the lowpermeability unit that overlies the main reservoir body, and these faults vent gas from the part of the reservoir at the base of well GC955-H to the fluid-flow pathways above, whereas the lack of comparable faults around GC955-Q result in trapped gas at the base of that well and an absence of gas charge to the shallower strata in that well. Dashed green lines on the interpreted data plots (right side) indicate the unconformity. The thick black dashed line on the uninterpreted plots (left side) 
indicates the junction between high-resolution 2D data (above) and industry 3D data (below), manually stitched together for this figure. Proprietary data (3D seismic images) courtesy of WesternGeco/Schlumberger.

Figure 7: Detail views of the chimneys and mud volcano near well GC955-H. Top left plot shows oblique view of seafloor (picked from industry 3D seismic data, proprietary data courtesy of WesternGeco/Schlumberger) and plotted with significant vertical exaggeration). Line 221 is shown in the lower left, with and without interpretations marked. Three chimney features are visible, but the easternmost of the three does not appear to extend to the seafloor. Line 145 is shown in the top right, and represents a slice essentially along the westernmost chimney feature; reflectivity in the area of the chimney is weak and incoherent. Line 153a (bottom right) does not intersect any of the chimneys, and it shows appreciably stronger and more coherent reflection character than line 145. Dashed green lines on the interpreted data plots indicate the unconformity that is discussed in the text.

Figure 8: Detailed view of lines 227 and 139, showing assemblage of proximal levee sediments in east-west and north-south orientations. Specific levee package interpretations are not definitive; the key interpretation is that the main reservoir body at GC955 is composed primarily of proximal levee deposits. 
Figure 9: This Gant chart illustrates the relative timing of important depositional, erosional and structural events at GC955, along with the timing of fluid flow. Dotted lines indicate timing uncertainties. Timing of $500 \mathrm{ka}$ for the channel/levee system being present at GC955 is based on Weimer and Dixon (1994).

Figure 10: These 2013 high-resolution seismic data from line 225a (same as shown in Figure 6) illustrate the gas hydrate volume calculation. The red line marks the picked top-of-reservoir surface that was picked on all 2D lines and interpolated between them, and the blue line indicates the position of the assumed base of gas hydrate stability (BGHS). Logs plotted along the wellbores show 2009 LWD data: gamma ray in green on the left side of the well bore line and ring resistivity in grey on the right side.

Figure 11: Logging-while-drilling (LWD) data from wells GC955-H (upper row) and GC955-Q (lower row) illustrate important aspects of the low-permeability unit overlying the main reservoir body, and the transition between the two. From left to right, the plots show: gamma ray measurements, $\mathrm{V}_{\text {shale }}$ (shale fraction) calculated from the gamma ray log as described in the text, formation resistivity as measured by the ring sensor of the geoVision tool (Collett et al., 2012), seismic P-wave velocity $\left(V_{p}\right)$ measured by the SonicScope acoustic tool (Collett et al., 2012), and the borehole diameter as measured by the caliper tool. The vertical dotted lines on the plots of gamma logs indicate the minimum and maximum values used for calculation of $\mathrm{V}_{\text {shale. }}$. The red line on the $\mathrm{V}_{\text {shale }}$ plot indicates a smoothed version of $\mathrm{V}_{\text {shale }}$ (median 
filter length approximately $6 \mathrm{~m}$ ). The vertical dotted lines on the caliper plots indicate the hole diameter above which the hole is considered to be sufficiently washed out that some log measurements may be impacted (nominal hole diameter is 8.5 inches). Horizontal dashed orange lines indicate the top and bottom of the low-permeability unit, and the red stars indicate the top of the main gas hydrate accumulation in each well. The gamma values observed in these washed out zones are indicated with dark blue dots in the gamma ray plots. The top of each plot is at the seafloor depth, for GC955-H the top of gas hydrate-saturated reservoir is at approximately $2462 \mathrm{~m}$ depth below Kelly bushing, and for GC955-Q the top of the gas hydrate-saturated reservoir is at approximately $2430 \mathrm{~m}$ below Kelly bushing. 


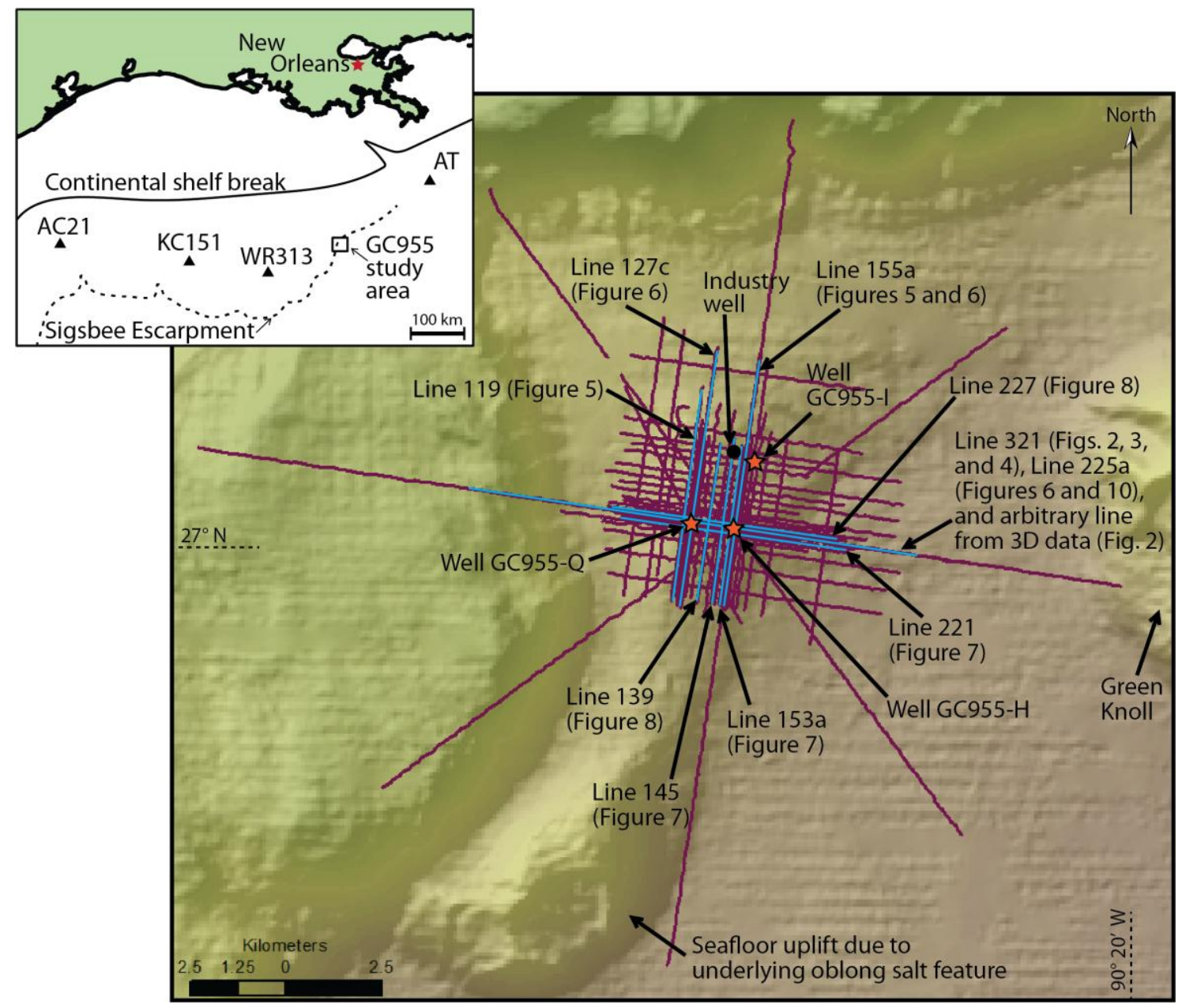

Figure 1: Map of the Green Canyon 955 study area showing 2D seismic survey lines and the three JIP LWD boreholes drilled in 2012. The full 2013 seismic survey layout is plotted as purple lines and the transects that are shown in this contribution are plotted as light blue lines. Inset map shows location within the Gulf of Mexico, as well as other areas studied by the Gulf of Mexico Gas Hydrate Joint Industry Project. 

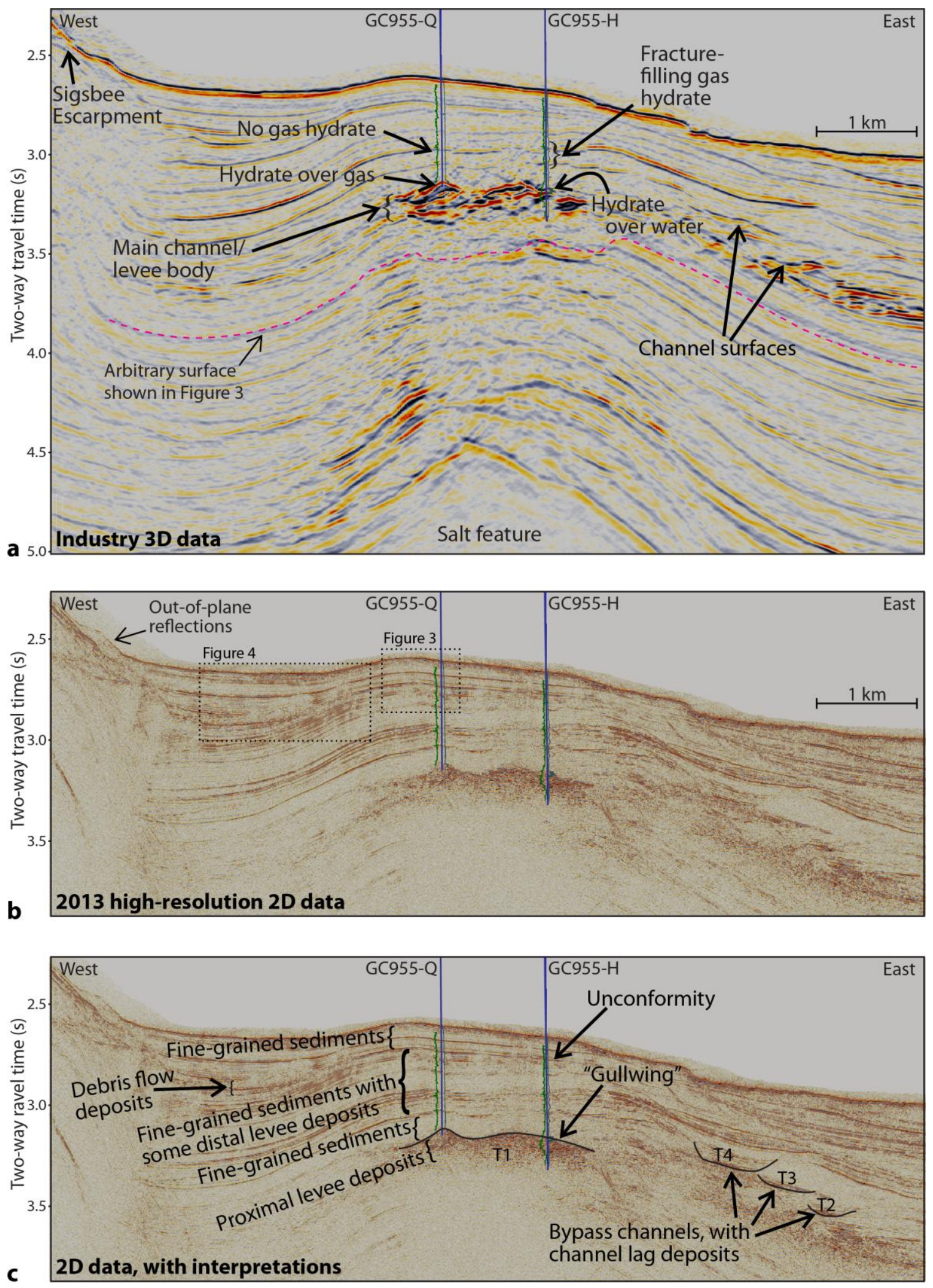
Figure 2: (a) Image extracted from the industry 3D seismic dataset, with relevant features marked, including JIP LWD boreholes GC955-Q and GC955-H, the main reservoir body, and the underlying salt feature that caused some of the structural deformation in the area. The dashed pink line indicates the horizon that is shown in Figure 5. Gamma ray (left) and resistivity (right) well logs are shown along the well bores. (b) High-resolution 2D image along the same transect, 2D line 321, showing similar features but at higher resolution and with less depth penetration. (c) 2D seismic data with geologic interpretations. Proprietary 3D data courtesy of WesternGeco/Schlumberger. 

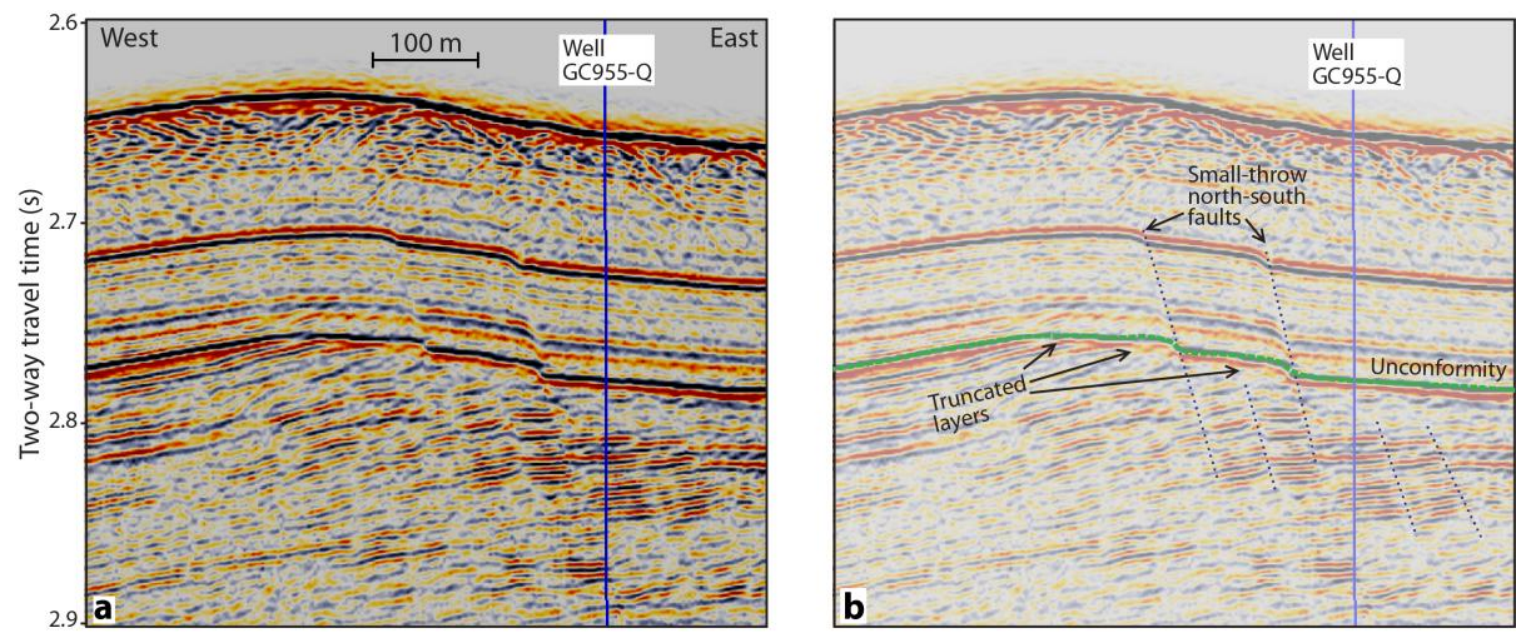

Figure 3. Detail from seismic line 321 (a), showing the unconformity and some of the small-throw north-south-oriented faults, as indicated on the annotated plot (b). Location of the data is indicated on Figure 2. 

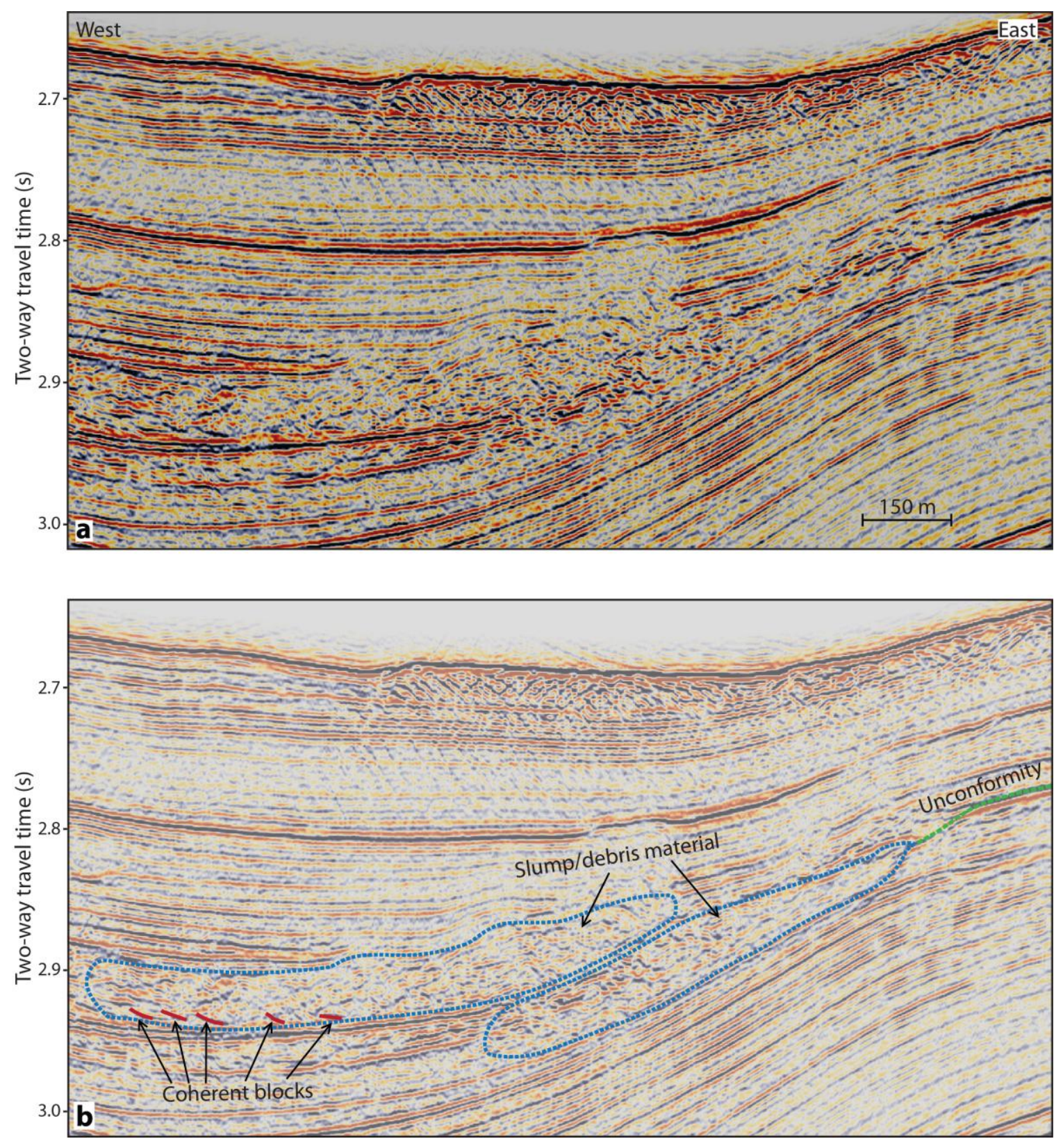

Figure 4. Detail from seismic line 321 in part (a), with annotated plot (b) showing debris flow material that has moved from up-slope. Location of the data is indicated on Figure 2. 
View looking downward to the west southwest

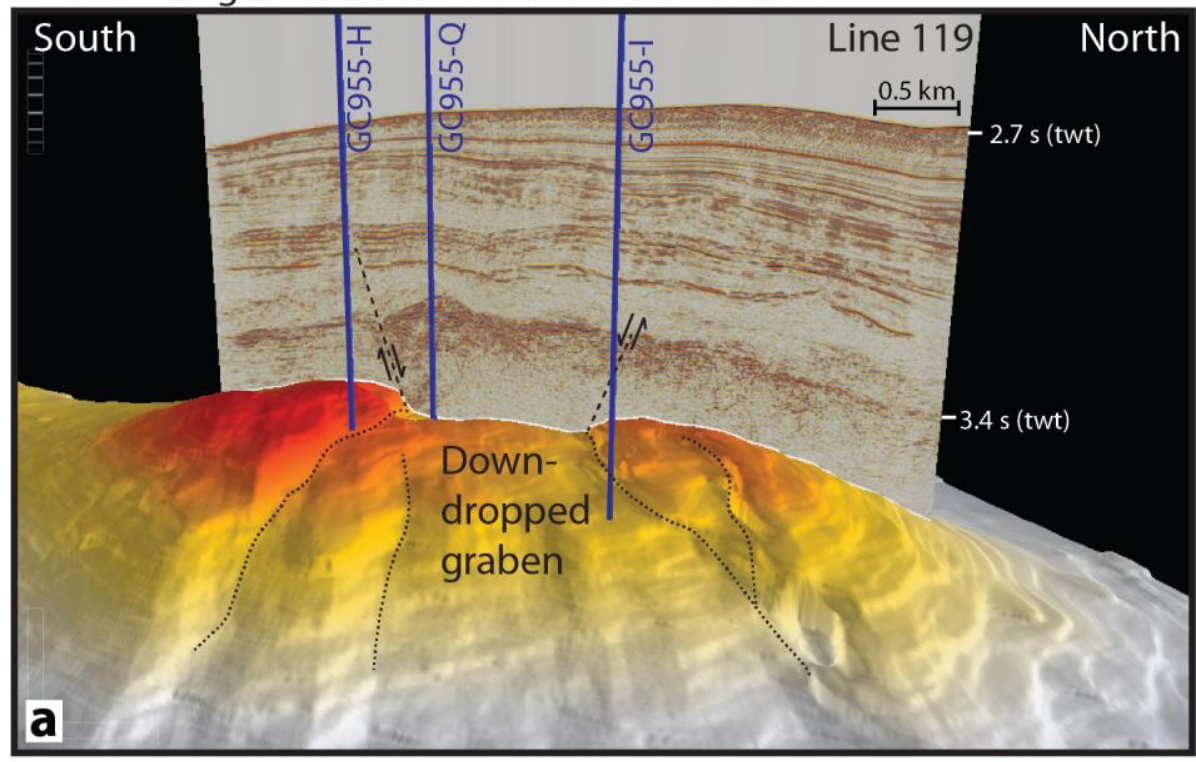

View looking downward to the east southeast

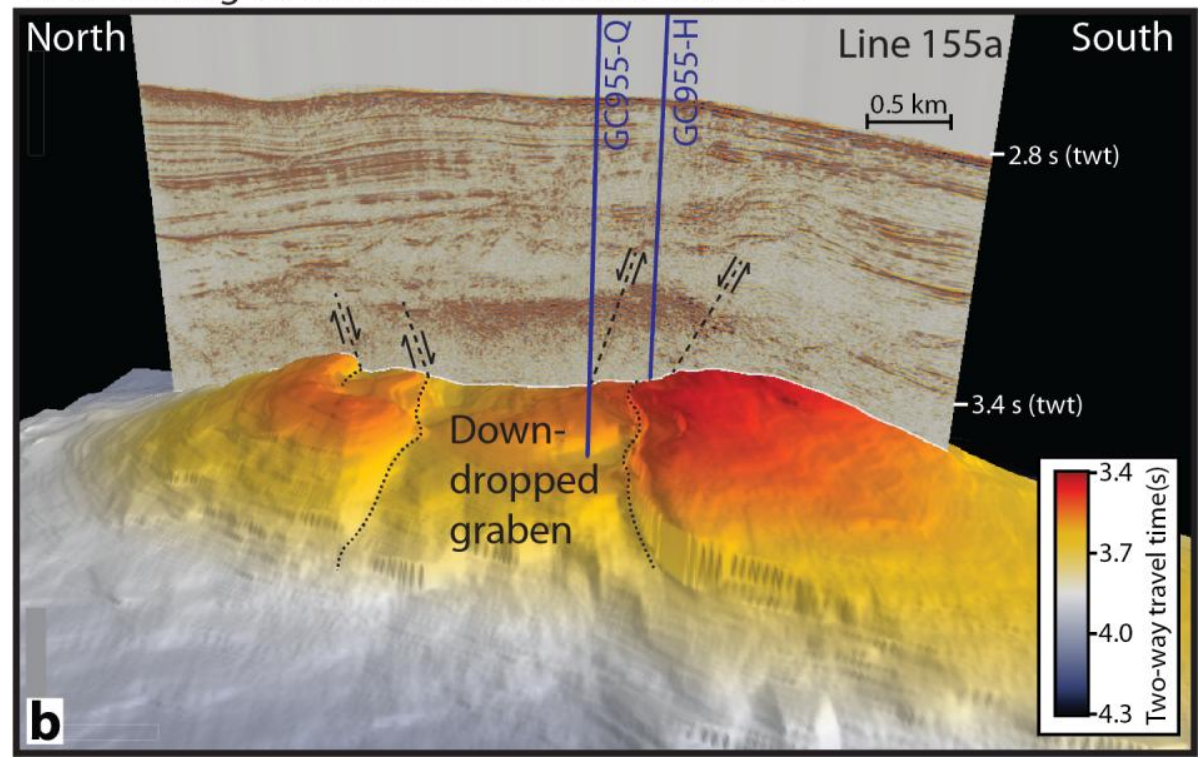

Figure 5: Two oblique views of the GC955 study area. In both parts of the figure, the colored surface is picked from the industry 3D data (proprietary data courtesy of WesternGeco/Schlumberger) and its position is indicated in Figure 2. Blue lines indicate the positions of the JIP LWD boreholes, and to help visualization in this perspective view, these lines are extended to the depth of the picked surface. In (a), 2D seismic line 119 is shown down to its intersection with the surface, and in (b) 2D 
seismic line $155 \mathrm{a}$ is shown. The down-dropped graben is labeled in both plots, with dashed lines indicating the bounding faults on the 2D seismic data and dotted lines indicating the positions of these faults on the 3D surface. Two-way seismic travel time (twtt) is marked on each seismic section. 

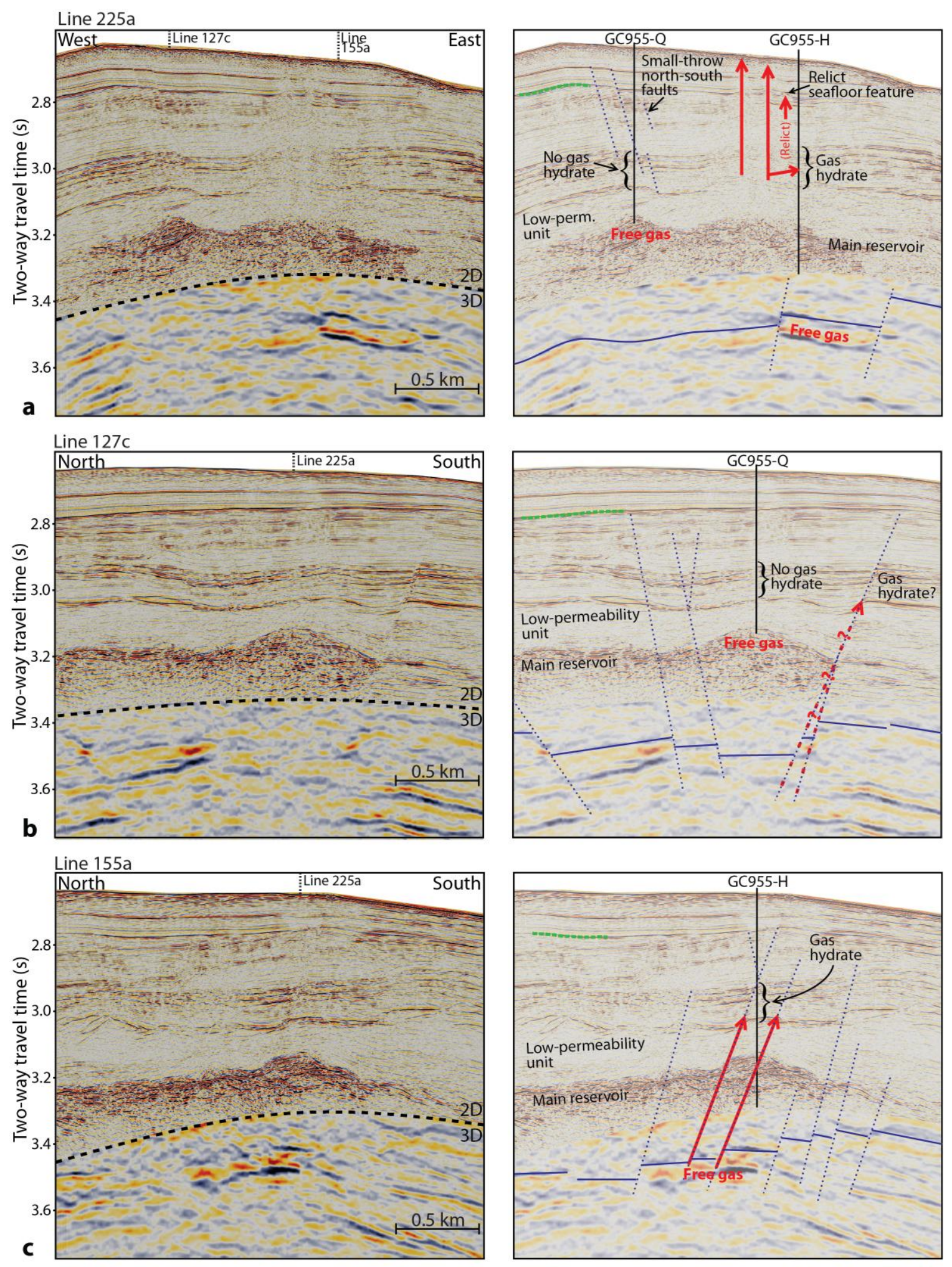

Figure 6: Three intersecting 2D seismic lines, illustrating key elements of the gas migration system at GC955. Line 225a (a) shows prominent chimney features just 
west of well GC955-H, indicating a gas source for the gas hydrate observed around depths between 3.0 and 3.1 seconds in that well. North-south lines 127c (b) and 155a (c ) reveal key distinctions between the areas of the two wells. The major (marked) faults allow gas flow (indicated by red arrows) through the lowpermeability unit that overlies the main reservoir body, and these faults vent gas from the part of the reservoir at the base of well GC955-H to the fluid-flow pathways above, whereas the lack of comparable faults around GC955-Q result in trapped gas at the base of that well and an absence of gas charge to the shallower strata in that well. Dashed green lines on the interpreted data plots (right side) indicate the unconformity. The thick black dashed line on the uninterpreted plots (left side) indicates the junction between high-resolution 2D data (above) and industry 3D data (below), manually stitched together for this figure. Proprietary data (3D seismic images) courtesy of WesternGeco/Schlumberger. 

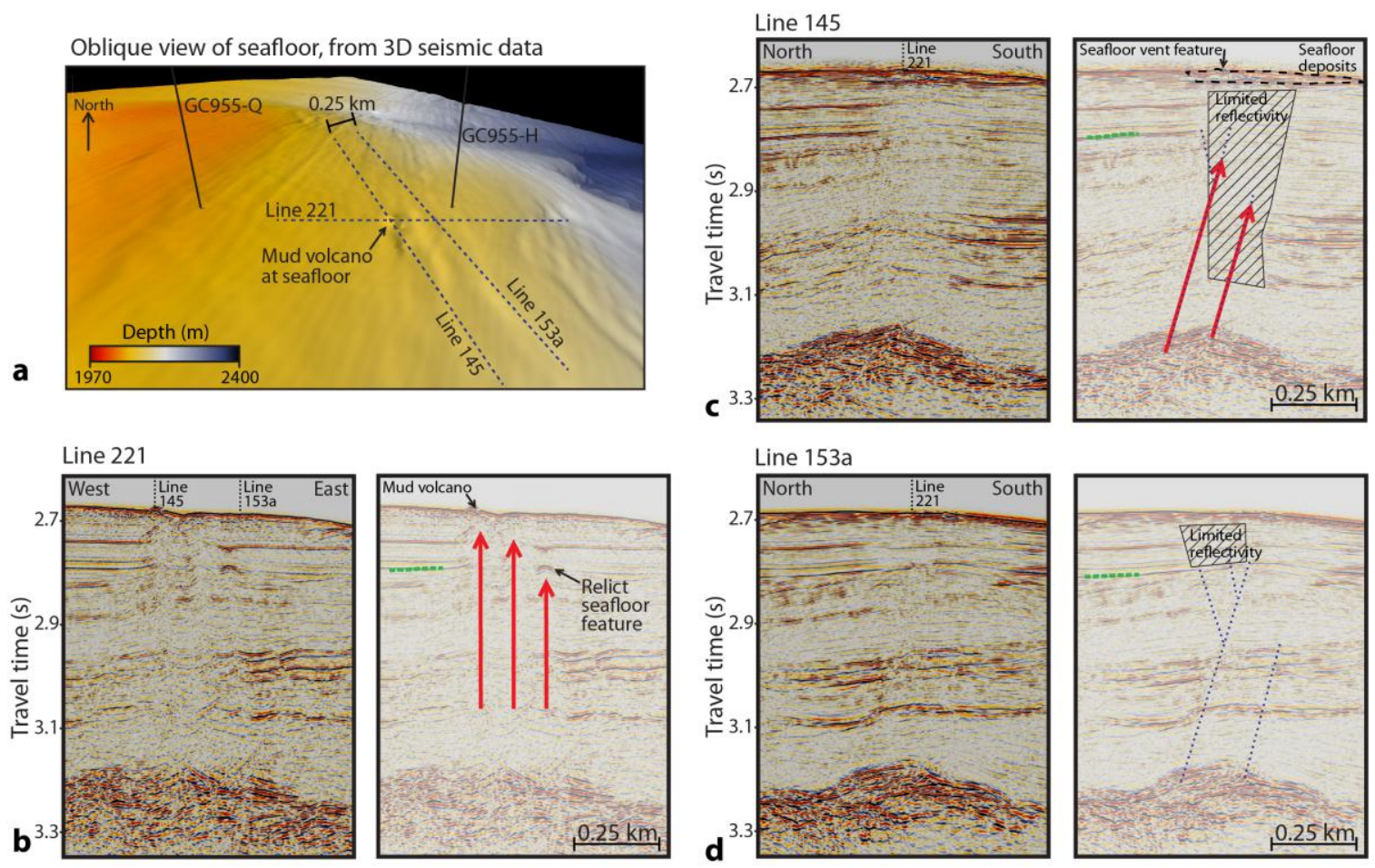

Figure 7: Detail views of the chimneys and mud volcano near well GC955-H. Top left plot shows oblique view of seafloor (picked from industry 3D seismic data, proprietary data courtesy of WesternGeco/Schlumberger) and plotted with significant vertical exaggeration). Line 221 is shown in the lower left, with and without interpretations marked. Three chimney features are visible, but the easternmost of the three does not appear to extend to the seafloor. Line 145 is shown in the top right, and represents a slice essentially along the westernmost chimney feature; reflectivity in the area of the chimney is weak and incoherent. Line 153a (bottom right) does not intersect any of the chimneys, and it shows appreciably stronger and more coherent reflection character than line 145. Dashed green lines on the interpreted data plots indicate the unconformity that is discussed in the text. 


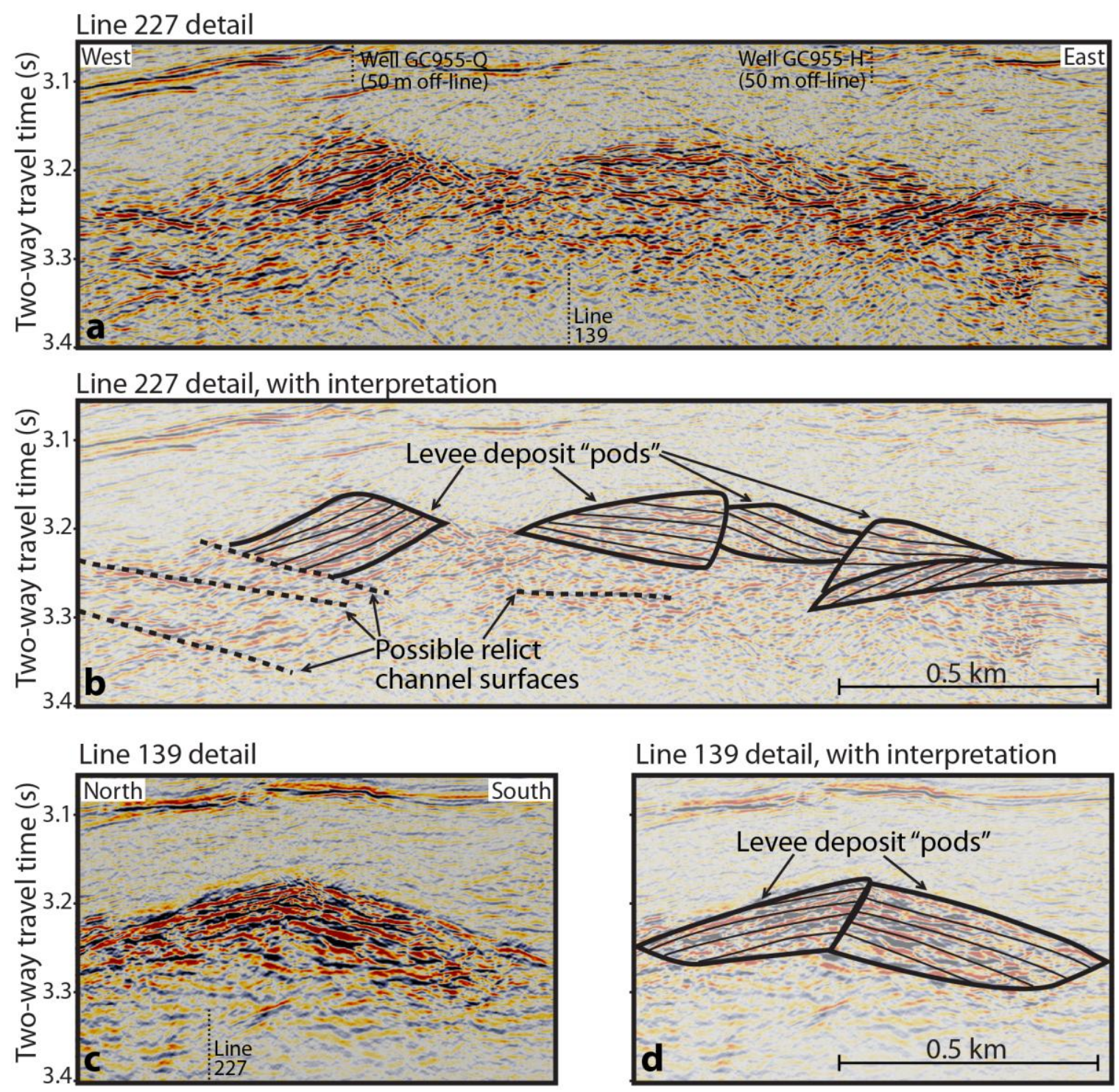

Figure 8: Detailed view of lines 227 and 139, showing assemblage of proximal levee sediments in east-west and north-south orientations. Specific levee package interpretations are not definitive; the key interpretation is that the main reservoir body at GC955 is composed primarily of proximal levee deposits. 
Fine-grained sedimentary deposition in area of JIP wells

Channel/levee processes in area of JIP wells, depositing sand-rich proximal levee facies

Fine-grained deposition in area of JIP wells, with some distal levee deposits

Bypass channels to the east, depositing channel lag, mud, and likely some sand

Salt-driven uplift beneath area of JIP wells

Down-drop of large E-W graben, and associated normal faulting

Gas charge in main sand reservoir

Focused fluid flow (chimney) activity

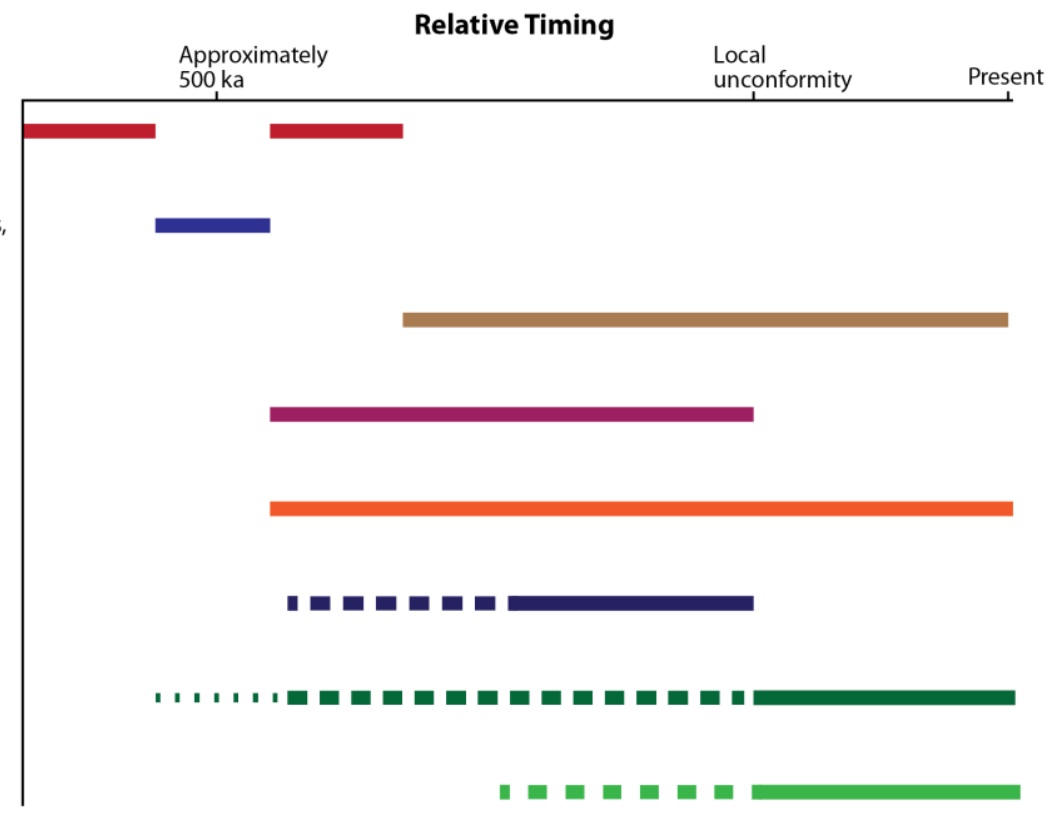

Figure 9: This Gant chart illustrates the relative timing of important depositional, erosional and structural events at GC955, along with the timing of fluid flow. Dotted lines indicate timing uncertainties. Timing of $500 \mathrm{ka}$ for the channel/levee system being present at GC955 is based on Weimer and Dixon (1994). 

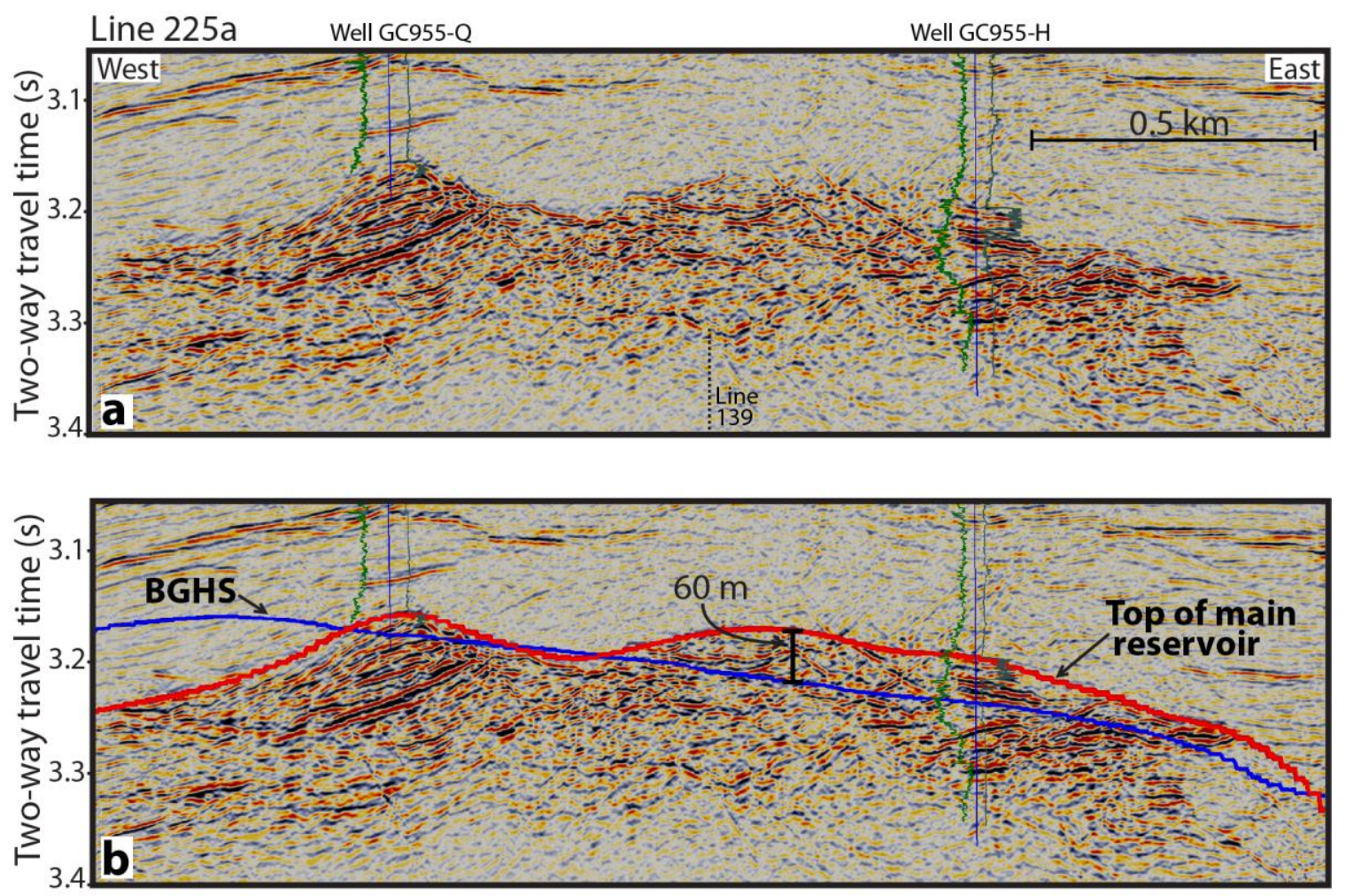

Figure 10: These 2013 high-resolution seismic data from line 225a (same as shown in Figure 6) illustrate the gas hydrate volume calculation. The red line marks the picked top-of-reservoir surface that was picked on all 2D lines and interpolated between them, and the blue line indicates the estimated base of gas hydrate stability (BGHS) used in gas volume calculations. Logs plotted along the wellbores show 2009 LWD data: gamma ray in green on the left side of the well bore line and ring resistivity in grey on the right side. 

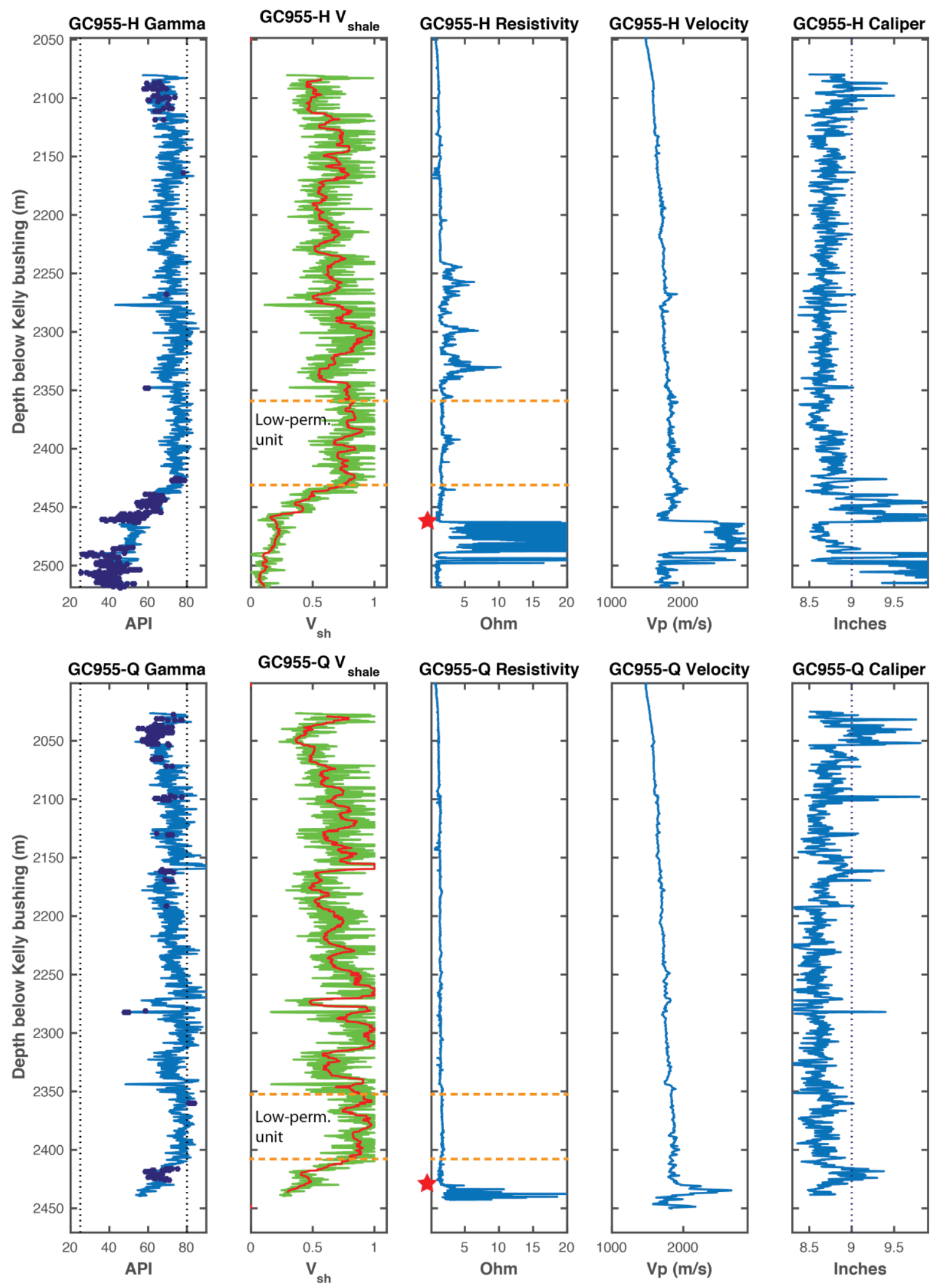

GC955-Q Resistivity

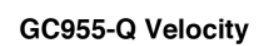

GC955-Q Caliper
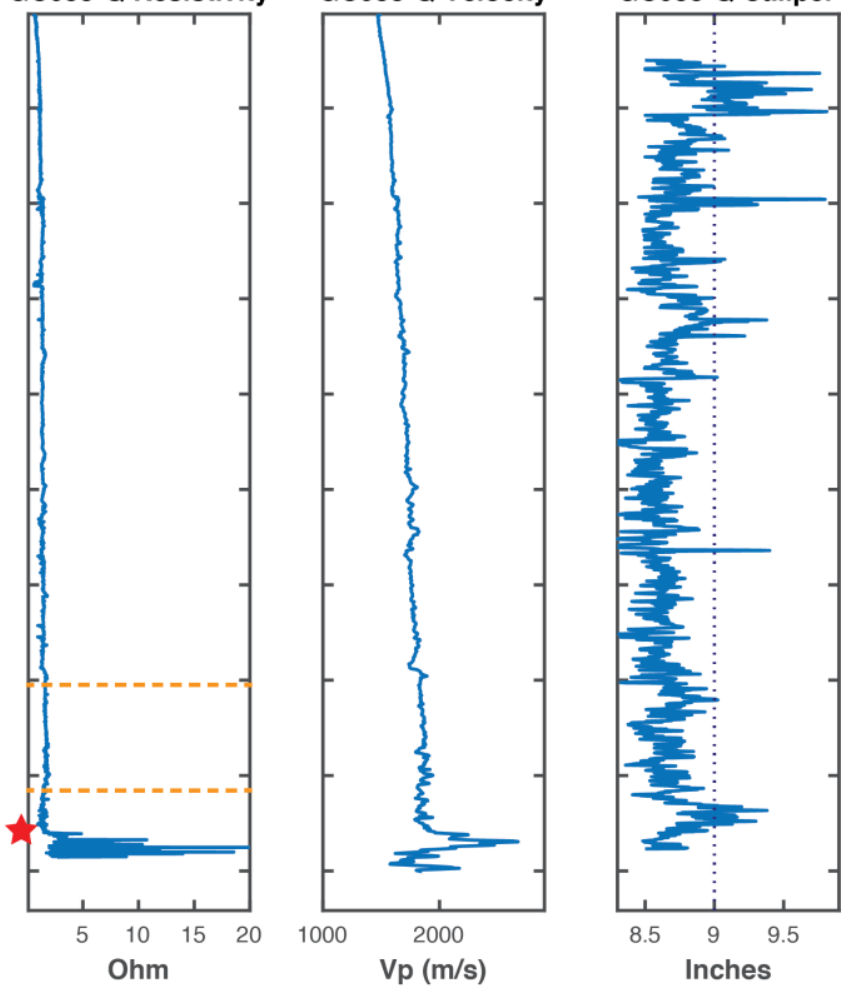
Figure 11: Logging-while-drilling (LWD) data from wells GC955-H (upper row) and GC955-Q (lower row) illustrate important aspects of the low-permeability unit overlying the main reservoir body, and the transition between the two. From left to right, the plots show: gamma ray measurements, $\mathrm{V}_{\text {shale }}$ (shale fraction) calculated from the gamma ray log as described in the text, formation resistivity as measured by the ring sensor of the geoVision tool (Collett et al., 2012), seismic P-wave velocity $\left(V_{p}\right)$ measured by the SonicScope acoustic tool (Collett et al., 2012), and the borehole diameter as measured by the caliper tool. The vertical dotted lines on the plots of gamma logs indicate the minimum and maximum values used for calculation of $V_{\text {shale. }}$ The red line on the $V_{\text {shale }}$ plot indicates a smoothed version of $V_{\text {shale }}$ (median filter length approximately $6 \mathrm{~m}$ ). The vertical dotted lines on the caliper plots indicate the hole diameter above which the hole is considered to be sufficiently washed out that some log measurements may be impacted (nominal hole diameter is 8.5 inches). Horizontal dashed orange lines indicate the top and bottom of the low-permeability unit, and the red stars indicate the top of the main gas hydrate accumulation in each well. The gamma values observed in these washed out zones are indicated with dark blue dots in the gamma ray plots. The top of each plot is at the seafloor depth, for GC955-H the top of gas hydrate-saturated reservoir is at approximately $2462 \mathrm{~m}$ depth below Kelly bushing, and for GC955-Q the top of the gas hydrate-saturated reservoir is at approximately $2430 \mathrm{~m}$ below Kelly bushing. 